\title{
IMAGEN Y PARTICIPACIÓN PRÁCTICA DE LAS OLLAS CON PATAS DEL VALLE DE HUALFÍN (CATAMARCA, ARGENTINA)
}

\author{
IMAGES AND PARTICIPATION OF FOOTED POTS FROM THE HUALFINN \\ VALLEY (CATAMARCA, ARGENTINA)
}

María Emila luccí, Federico WynveldT ${ }^{8}$

\begin{abstract}
El presente estudio se desarrolla a partir de la identificación de un grupo de vasijas de cerámica ordinaria con aditamentos modelados, de aparición frecuente en momentos tardíos prehispánicos del Valle de Hualfín, en el Noroeste Argentino. Se enfoca en la caracterización de las piezas, el análisis semiótico de la imagen modelada y los contextos arqueológicos de los hallazgos. En las imágenes se reconocen referencias a los camélidos, animales cuya presencia para los momentos tardíos es circunstancial. La investigación de sus contextos permite asociar estas vasijas a prácticas funerarias, de preparación y consumo de comida y de tradiciones de manufactura alfarera.

Palabras clave: Noroeste Argentino, Valle de Hualfín, Cerámica, Semiótica, Camélidos.
\end{abstract}

This paper presents the results of a study of non painted and rugged wares ceramic vessels from the Hualfin Valley area in Northwestern Argentina. We identify a particular set of vessels with modeled details and include a characterization of the pots, a semiotic analysis of their modeled images, and a description of the archaeological contexts in which they were found. On the vessels we identified references to camelids, animals that played a leading role in images from earlier times but that are only circumstantially present at later times. By examining the contexts of the vessels, we are able associate the vessels with funerary practices, food consumption, and ceramic manufacturing traditions.

Keywords: Northwestern Argentina, Hualfin Valley, Ceramics, Semiotics, Camelids.

\section{INTRODUCCIÓN}

El repertorio de vasijas producidas y usadas por los antiguos habitantes de la región valliserrana del Noroeste Argentino durante los momentos prehispánicos tardíos, históricamente fue dividido en dos grandes grupos: la cerámica fina y la ordinaria. La cerámica fina está representada por conjuntos como el Belén, el Santa María y el Sanagasta, entre otros. El proceso de identificación, descripción y análisis de estos tipos de cerámica tiene una importante trayectoria (Lafone Quevedo 1892, Bregante 1926, Serrano 1958), y a partir de su característica regionalización y variabilidad se definieron culturas, contactos culturales y secuencias cronológicas (González 1955, Podestá \& Perrota 1973). Las profusas manifestaciones de imágenes pintadas recibieron atención y fueron estudiadas en detalle (Quiroga \& Puente 2007, Nastri 2008, Basile 2009, Wynveldt 2009, entre otros). El caso del segundo conjunto, el de la cerámica ordinaria, es diferente. Si bien está asociada a la alfarería fina en la mayor parte de los contextos, raramente fue considerada como caso de estudio, y solo comenzó a

A María Emilia Iucci, Laboratorio de Análisis Cerámico, Facultad de Ciencias Naturales y Museo, Universidad Nacional de La PlataCONICET. Calle 64 N$^{\circ} 3$ La Plata (1900). Email: emiliaiucci@yahoo.com.ar

B Federico Wynveldt, Laboratorio de Análisis Cerámico, Facultad de Ciencias Naturales y Museo, Universidad Nacional de La PlataCONICET. Calle 64 №3 La Plata (1900). Email: wynveldtf@fcnym.unlp.edu.ar 
ser contemplada cuando el foco de interés arqueológico general logró trascender las problemáticas cronológicas y de difusión entre las culturas.

En el marco de las investigaciones sobre las ocupaciones tardías del Valle de Hualfín (Departamento de Belén, Provincia de Catamarca, Noroeste de Argentina), dentro de este repertorio de cerámica ordinaria delimitamos un grupo particular en vista de su morfología y aditamentos modelados, al que denominamos "ollas con patas". Se trata de vasijas de cuerpo de forma elipsoide u ovaloide, restringidas, con tres o cuatro apéndices que soportan el cuerpo y que pueden tener una incisión o escotadura que subdivide en dos al extremo en el sector de apoyo. La combinación de estos elementos y sus detalles, que serán analizados a lo largo de este trabajo, nos llevan a considerar que el conjunto de la vasija remite probablemente a un camélido.

Estas piezas habían sido mencionadas ocasionalmente en la literatura sobre la región valliserrana del Noroeste Argentino y, recientemente, se las documentó en entierros de época tardía del Valle de Hualfín. Su incorporación a la materialidad de las poblaciones tardías se hizo ineludible en el momento en que comenzaron a visibilizarse con mayor frecuencia en el registro no funerario, en muchas de las estructuras excavadas en los antiguos poblados del valle, asociadas a la cerámica Belén y con dataciones que rondan los siglos Xv y xvI.

En el contexto de un trabajo orientado a analizar las imágenes de la alfarería tardía del Valle de Hualfín, sus procesos de producción y sus posibles usos y ámbitos de acción práctica, se presentan algunas líneas de análisis que permiten incluir a estas piezas en un grupo cerámico particular, interpretar la referencia de las imágenes e insertarlas en redes de participación de la vida de la época.

\section{El abordaje de la cerámica ordinaria tardía}

En las narrativas clásicas de la historia prehispánica del Noroeste Argentino, el estudio de los materiales cerámicos estuvo sujeto a su uso como indicador cronológico y espacial (Balesta \& Williams 2007, Balesta 2015). Este foco de interés tuvo particular relevancia para el Valle de Hualfín (fig. 1), dado que fue el lugar elegido para la construcción de la primera secuencia cronológica moderna para la región (González 1955, González \& Cowgill 1975). La cerámica ordinaria no fue considerada como un elemento relevante en vista de esos objetivos. Si bien tiene una buena representatividad en las colecciones de las que se obtuvo la información de base para la realización de las secuencias, muy raramente tuvo un carácter destacado en la bibliografía. Las bases en "pie de compotera" constituyen una de las excepciones, dado que son porciones del cuerpo de algunas piezas ordinarias a las que generalmente se les otorgó significación cronológica (Debenedetti 1921, Tarragó 1984, discutido por Marchegiani 2011 e Iucci 2013). No obstante, lo más habitual fue que la cerámica ordinaria fuera mencionada solo de manera ocasional, sin que se llevara a cabo un examen con fines analíticos.

Esta situación comenzó a revertirse con las investigaciones sobre temas específicos del material cerámico y su relación con los distintos ámbitos de la vida social, a partir de las que se dio inicio a los abordajes sistemáticos de la cerámica ordinaria tardía desde diversas aproximaciones (Piñeiro 1996, Zagorodny 1996, Marchegiani \& Greco 2007, Iucci 2009, Iucci et al. 2010, Páez 2010, De La Fuente 2011, Puente 2012, Iucci 2013). En particular, se logró identificar regularidades importantes en las pastas, los acabados de superficie, las morfologías y las dimensiones, que permitieron percibir una apariencia de uniformidad del conjunto en una escala regional (Puente 2012, Iucci 2013). En este contexto, la mayor atención que se le dedicó a esta cerámica ha estado enfocada en los estudios acerca de la organización de la producción alfarera, el uso de contenedores en diferentes instancias de las prácticas domésticas y funerarias, y el abordaje de las identidades (p.ej. De La Fuente 2011, Puente 2012, Iucci 2013).

Desde el inicio de nuestras investigaciones sobre las prácticas sociales vinculadas a la alfarería tardía del Valle de Hualfín, el esfuerzo por analizar materiales de diferentes lugares y contextos, reconstruir exhaustivamente vasijas a partir de fragmentos $y$, fundamentalmente, comparar y buscar las asociaciones entre los distintos conjuntos a través de diferentes niveles de estudio, ha sido una de las claves para tener una idea más precisa acerca de la materialidad de los habitantes del valle. Fue en el marco de este trabajo que se reunió un pequeño número de ollas con patas y se llegó a una primera caracterización general de estas piezas como grupo.

Una mirada global de este conjunto de vasijas permite notar que la mayoría "representa algo". El hecho de intentar reconocer al referente de una representación en una imagen permite explorar un aspecto que ha sido 


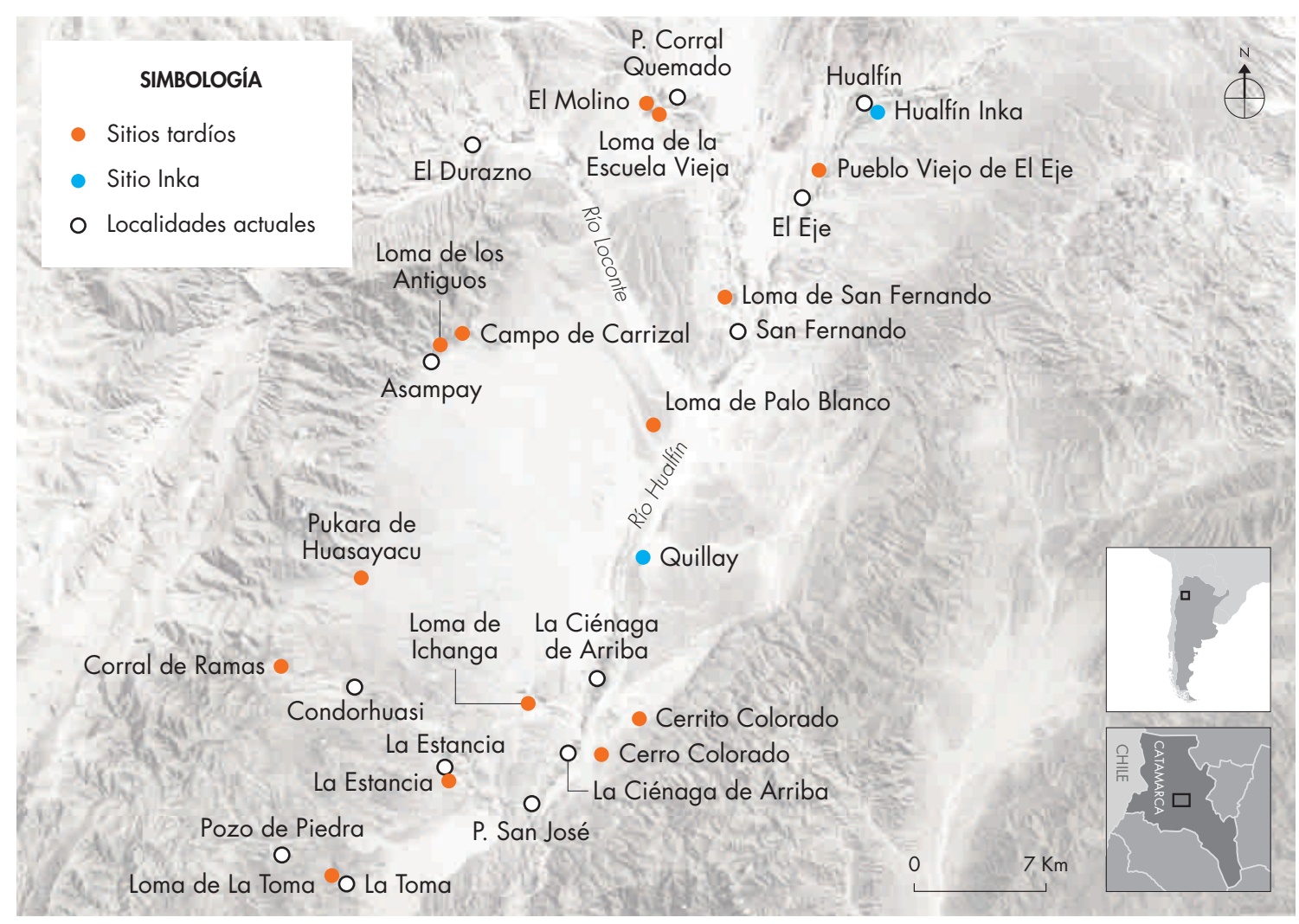

Figura 1. Mapa del Valle de Hualfín con las principales localidades y sitios mencionados en el texto. Figure 1. Map of the Hualfin Valley and the main localities and sites mentioned in the text.

poco analizado para la cerámica ordinaria tardía. Por otra parte, el tipo de soporte en el que está plasmada la imagen, junto con el cual actúa simultáneamente, es un tipo de objeto móvil, manipulable, que está construido de maneras particulares y que tiene la capacidad de contener sustancias. Es decir, son objetos que participan como mediadores -objetos que transforman, traducen, interfieren activamente en las situaciones en las que se los involucra- en una extensa red de relaciones (Latour 2008).

Con estas consideraciones en cuenta, para el análisis de las imágenes optamos por aplicar lineamientos conceptuales y metodológicos que pudieran articularse con la construcción de esta red. Las herramientas propuestas por Magariños de Morentín (2001, 2008) para el desarrollo de una semiótica de la imagen visual permiten esta articulación, ya que implican la puesta en marcha de un procedimiento que va desde la identificación de los elementos componentes de la imagen, pasando por el reconocimiento de los referentes de las representaciones, hasta la interpretación de la imagen como producto de la interrelación con otras semiosis vigentes en determinado momento de determinada sociedad. Este proceso de interpretación es análogo al ejercicio de situar a las imágenes -y a las vasijas- en sus contextos particulares de participación. Esta perspectiva semiótica y la metodología de análisis propuestas por Magariños de Morentín $(2001,2008)$ han sido aplicadas a diferentes casos arqueológicos del NOA (Balesta 2000, 2015; Wynveldt 2009; Martel \& Giraudo 2014; Zaburlín 2016).

Para analizar el grupo de ollas con patas desde el punto de vista de la semiótica, se las conceptualiza como un signo. Y para su consideración como objeto de estudio de una semiótica de la imagen visual, la definimos como un tipo particular de signo, una imagen material visual. Según Magariños de Morentín (2001: 297), este tipo de imagen es "una propuesta de percepción visual (algo), considerada como representación (que está en alguna relación), destinada a la configuración de una forma (por algo), para su valoración por el perceptor 
(para alguien)". Su referencia a un existente -su carácter de ícono- nos permite conceptualizarla más específicamente como una imagen material visual figurativa. Para su análisis se identifican marcas (las unidades mínimas que componen la imagen y que pueden describirse independientemente de su integración en una representación), se reconocen atractores (mínimo acervo de rasgos gráficos que forman la representación), y se analiza la participación de las vasijas y sus imágenes en el ámbito de la práctica. De esta manera, desde la caracterización de los objetos cerámicos y el análisis de las imágenes, es posible extendernos hacia una serie amplia de relaciones específicas de participación práctica, dadas por su contexto de producción, los usos particulares, las asociaciones, la distribución espacial y la cronología.

\section{El grupo de las ollas con patas en el conjunto ordinario del Valle de Hualfín}

La distinción de este grupo de ollas se realizó una vez iniciado el estudio en profundidad de la alfarería ordinaria. Ante la ausencia de un conjunto cerámico de referencia, existía la incógnita sobre una serie de fragmentos hallados entre los materiales de algunas estructuras arqueológicas que no podían ser asociados con formas o sectores conocidos de vasijas. Recién a partir de la identificación de cerámica entera de colección, de la reconstrucción de vasijas bien representadas y de un examen minucioso de sus sectores constitutivos, se logró reconocer el tipo de piezas y los sectores morfológicos a los que corresponden los fragmentos.

Se definió una muestra con procedencia en el Valle de Hualfín que incluye vasijas completas localizadas en la Colección Benjamín Muñiz Barreto del Museo de La Plata (Universidad Nacional de La Plata, Argentina), mayoritariamente correspondientes a contextos funerarios. La particularidad de esta colección es el importante grado de documentación producida a través de un registro minucioso, realizado durante las tareas de excavación llevadas a cabo en la década de 1920 (Balesta 2000). También se tomaron materiales fragmentarios -que fueron exhaustivamente reconstruidos- que proceden de excavaciones y fragmentos cerámicos de recolecciones superficiales, recuperados por A. R. González entre las décadas de 1950 y 1970, y por nuestro equipo de trabajo a partir de 1995 en los antiguos poblados del área. Así quedó conformada una muestra de 15 ejemplares con una procedencia conocida y segura, y con diferentes grados de representación (fig. 2, Tabla 1): completas, bien representadas (cuando se pudo reconstruir al menos una porción del cuerpo) e identificadas (cuando se hicieron presentes solo en el nivel de unos pocos fragmentos). La frecuencia de aparición de estas piezas es baja, fueron halladas en solo 7 recintos, sobre un total de aproximadamente 60 excavados. No obstante, teniendo en cuenta que los elementos claramente diagnósticos del grupo pueden no estar presentes entre los fragmentos de una estructura, mientras que otros sectores no se diferencian del resto de las vasijas ordinarias, no se descarta una eventual sub-representación de la proporción de piezas efectivamente halladas.

Por otro lado, en una búsqueda aún no exhaustiva, se localizaron estas ollas o algunas de sus partes entre los materiales de otras colecciones (fig. 3) y en publicaciones sobre contextos cerámicos tardíos de zonas aledañas, como los valles del Bolsón, Yocavil, Cajón y la zona de Tinogasta. La información con la que contamos para estos casos es dispar (tabla 2), pero algunos fueron claves para reconocer atractores entre el material fragmentario del que partimos.

Entre la cerámica tardía de la zona, incluimos estas vasijas dentro del grupo de alfarería ordinaria, dado que comparten muchas de sus características y pueden vincularse con una misma tradición de manufactura. Este grupo fue definido como de manufactura local, junto con la cerámica Belén (Iucci 2013), cerámica de superficies lisas - muchas veces pulidas-y pintadas, que conforma el soporte más abundante de imágenes de las sociedades tardías del valle (Wynveldt 2009) y que se asocia en todos los sitios y tipos de contexto a la ordinaria.

El conjunto de vasijas ordinarias presenta acabados de superficie externa alisados, rugosos, estriados o con inclusiones grandes y conspicuas; mientras que la superficie interna generalmente es alisada. No posee pintura -salvo casos aislados- ni pulimento, y habitualmente presenta depósitos de hollín en alguna de sus superficies. Más allá de la falta de pintura, las texturas particulares que se logran a través de los acabados, y su combinación con la coloración que le otorga el hollín (cuando se encuentra) permiten suponer que estas rugosidades, además de incrementar las aptitudes de funcionamiento mecánico de las vasijas, le imprimen cualidades estéticas visibles y táctiles. Entre los tipos morfológicos se distinguen algunos muy estructurados como, por ejemplo, algunas formas de tinajas. Las pastas 
Tabla 1. Muestra, principales características y asociaciones de las ollas con patas con procedencia segura del Valle de Hualfín. Table 1. Sample, main characteristics and associations of the footed pots with confirmed provenance in the Hualfin Valley.

\begin{tabular}{|c|c|c|c|c|c|c|c|c|c|}
\hline PIEZA & SITIO & LOCALIDAD & $\begin{array}{c}\text { GRADO DE } \\
\text { REPRESENTACIÓN }\end{array}$ & $\begin{array}{c}\text { SECTOR } \\
\text { REPRESENTADO }\end{array}$ & \begin{tabular}{|} 
TAMAÑO \\
DE LA \\
PIEZA
\end{tabular} & $\begin{array}{c}\text { FORMA } \\
\text { DEL } \\
\text { CUERPO }\end{array}$ & $\begin{array}{l}\text { CANTIDAD } \\
\text { DE PATAS }\end{array}$ & $\begin{array}{c}\text { FORMA } \\
\text { DE PATA } \\
\text { (cortes en } \\
\mathrm{a} / \mathrm{b} / \mathrm{c} \text { ) }\end{array}$ & $\begin{array}{l}\text { CERÁMICA } \\
\text { ASOCIADA }\end{array}$ \\
\hline $\begin{array}{l}\mathrm{CBMB} \\
6357\end{array}$ & - & $\begin{array}{c}\text { Puerta } \\
\text { de Corral } \\
\text { Quemado }\end{array}$ & Completa & - & Muy chica & $\begin{array}{l}\text { Elipsoide de } \\
\text { eje horizontal, } \\
\text { con cuello }\end{array}$ & 3 & Cilíndrica & $\begin{array}{c}\text { Tinaja ordinaria, } \\
\text { olla Belén, puco } \\
\text { sin determinar }\end{array}$ \\
\hline $\begin{array}{l}\text { CBMB } \\
6469\end{array}$ & - & $\begin{array}{c}\text { Puerta } \\
\text { de Corral } \\
\text { Quemado }\end{array}$ & Completa & - & Muy chica & $\begin{array}{l}\text { Elipsoide de } \\
\text { eje horizontal, } \\
\text { con cuello }\end{array}$ & 4 & Cilíndrica & $\begin{array}{l}\text { Tinaja y puco } \\
\text { ordinarios }\end{array}$ \\
\hline $\begin{array}{l}\text { CBMB } \\
6971\end{array}$ & - & $\begin{array}{c}\text { Los } \\
\text { Nacimientos }\end{array}$ & Completa & - & Muy chica & $\begin{array}{l}\text { Elipsoide de } \\
\text { eje horizontal, } \\
\text { sin cuello }\end{array}$ & 4 & Cilíndrica & Sin determinar \\
\hline $\begin{array}{c}\text { CBMB } \\
10010\end{array}$ & - & La Ciénaga & Completa & - & Muy chica & $\begin{array}{l}\text { Esférica, con } \\
\text { cuello }\end{array}$ & 3 & Cilíndrica & Sin determinar \\
\hline $\begin{array}{l}\text { LI } 9 \\
\text { Ord A }\end{array}$ & $\begin{array}{l}\text { Loma de } \\
\text { Ichanga }\end{array}$ & La Ciénaga & Bien representada & Cuerpo y patas & Mediana & $\begin{array}{l}\text { Elipsoide de } \\
\text { eje horizontal, } \\
\text { con cuello }\end{array}$ & 3 & $\begin{array}{l}\text { Rectángulo/ } \\
\text { rectángulo/ } \\
\text { óvalo }\end{array}$ & $\begin{array}{l}\text { Olla con patas } \\
\text { LI } 9 \text { Ord B, } \\
\text { olla ordinaria } \\
\text { ovaloide, olla } \\
\text { Belén }\end{array}$ \\
\hline $\begin{array}{l}\text { LI } 9 \\
\text { Ord B }\end{array}$ & $\begin{array}{l}\text { Loma de } \\
\text { Ichanga }\end{array}$ & La Ciénaga & Bien representada & Cuerpo y patas & Chica & $\begin{array}{l}\text { Ovaloide, } \\
\text { con eje } \\
\text { vertical }\end{array}$ & 3 & $\begin{array}{l}\text { Triángulo/ } \\
\text { rectángulo } \\
\text { con leve } \\
\text { curvatura/ } \\
\text { óvalo }\end{array}$ & $\begin{array}{l}\text { Olla con patas } \\
\text { LI } 9 \text { Ord A, } \\
\text { olla ordinaria } \\
\text { ovaloide, olla } \\
\text { Belén }\end{array}$ \\
\hline $\begin{array}{l}\text { CC } 2 \\
\text { Ord B }\end{array}$ & $\begin{array}{l}\text { Cerro } \\
\text { Colorado }\end{array}$ & La Ciénaga & Bien representada & $\begin{array}{l}\text { Una pata }+ \\
\text { porción inferior } \\
\text { del cuerpo }\end{array}$ & Mediana? & - & - & $\begin{array}{c}\text { Triángulo/ } \\
\text { rectángulo/ } \\
\text { óvalo }\end{array}$ & $\begin{array}{c}\text { Cerámica Belén, } \\
\text { ordinaria, } \\
\text { Quirquincho } \\
\text { modelado }\end{array}$ \\
\hline $\begin{array}{l}\text { CC } 2 \\
\text { Ord C }\end{array}$ & $\begin{array}{l}\text { Cerro } \\
\text { Colorado }\end{array}$ & La Ciénaga & Identificada & $\begin{array}{l}\text { Porción de una } \\
\text { pata }\end{array}$ & $\begin{array}{c}\text { Muy } \\
\text { pequeña/ } \\
\text { pequeña }\end{array}$ & - & - & $\begin{array}{l}\text { Rectángulo/ } \\
\text { rectángulo/ } \\
\text { óvalo }\end{array}$ & $\begin{array}{c}\text { Cerámica Belén, } \\
\text { ordinaria, } \\
\text { Quirquincho } \\
\text { modelado }\end{array}$ \\
\hline $\begin{array}{l}\text { CC } 54 \\
\text { Ord B }\end{array}$ & $\begin{array}{l}\text { Cerro } \\
\text { Colorado }\end{array}$ & La Ciénaga & Identificada & $\begin{array}{l}\text { Porción de una } \\
\text { pata }\end{array}$ & $\begin{array}{c}\text { Muy } \\
\text { pequeña/ } \\
\text { pequeña }\end{array}$ & - & - & $\begin{array}{c}\text { Triángulo/ } \\
\text { rectángulo/ } \\
\text { óvalo }\end{array}$ & $\begin{array}{c}\text { Cerámica Belén, } \\
\text { ordinaria, Santa } \\
\text { María }\end{array}$ \\
\hline $\begin{array}{l}\text { Bsur } 1 \\
\text { Ord B }\end{array}$ & $\begin{array}{l}\text { Barranca } \\
\text { Sur }\end{array}$ & La Ciénaga & Bien representada & $\begin{array}{c}\text { Una pata }+ \\
\text { porción inferior } \\
\text { del cuerpo }\end{array}$ & $\begin{array}{c}\text { Muy } \\
\text { pequeña }\end{array}$ & - & - & Cilíndrica & $\begin{array}{l}\text { Cerámica sin } \\
\text { determinar }\end{array}$ \\
\hline $\begin{array}{l}\text { EM } 68 \\
\text { Ord K }\end{array}$ & El Molino & $\begin{array}{l}\text { Puerta } \\
\text { de Corral } \\
\text { Quemado }\end{array}$ & Identificada & $\begin{array}{l}\text { Cuello con } \\
\text { cabeza }\end{array}$ & Mediana? & - & - & - & $\begin{array}{c}\text { Cerámica Belén, } \\
\text { ordinaria, Santa } \\
\text { María }\end{array}$ \\
\hline $\begin{array}{c}\text { EM } 68 \\
\text { Ord J }\end{array}$ & El Molino & $\begin{array}{l}\text { Puerta } \\
\text { de Corral } \\
\text { Quemado }\end{array}$ & $\begin{array}{c}\text { Bien } \\
\text { representada }\end{array}$ & Cuerpo & $\begin{array}{c}\text { Muy } \\
\text { pequeña }\end{array}$ & $\begin{array}{l}\text { Elipsoide, con } \\
\text { eje horizontal }\end{array}$ & - & - & $\begin{array}{c}\text { Cerámica Belén, } \\
\text { ordinaria, Santa } \\
\text { María }\end{array}$ \\
\hline $\begin{array}{l}\text { EM } 98 \\
\text { Ord E }\end{array}$ & El Molino & $\begin{array}{l}\text { Puerta } \\
\text { de Corral } \\
\text { Quemado }\end{array}$ & Identificada & $\begin{array}{l}\text { Una pata + una } \\
\text { porción de pata }\end{array}$ & Mediana & - & - & $\begin{array}{l}\text { Rectángulo/ } \\
\text { rectángulo/ } \\
\text { óvalo }\end{array}$ & $\begin{array}{c}\text { Cerámica Belén, } \\
\text { ordinaria, Santa } \\
\text { María }\end{array}$ \\
\hline $\begin{array}{l}\text { EM S } \\
\text { Ord } 4\end{array}$ & El Molino & $\begin{array}{c}\text { Puerta } \\
\text { de Corral } \\
\text { Quemado }\end{array}$ & Identificada & pata & Mediana & - & - & $\begin{array}{c}\text { Rectángulo/ } \\
\text { rectángulo } \\
\text { o con leve } \\
\text { curvatura/ } \\
\quad \text { óvalo }\end{array}$ & - \\
\hline $\begin{array}{l}\text { PB S } \\
\text { Ord } 2\end{array}$ & $\begin{array}{l}\text { Palo } \\
\text { Blanco }\end{array}$ & Palo Blanco & Identificada & $\begin{array}{l}\text { dos porciones } \\
\text { de patas }\end{array}$ & $\begin{array}{c}\text { Muy } \\
\text { pequeña/ } \\
\text { pequeña }\end{array}$ & - & - & $\begin{array}{l}\text { Triángulo/ } \\
\text { rectángulo/ } \\
\text { óvalo }\end{array}$ & - \\
\hline
\end{tabular}




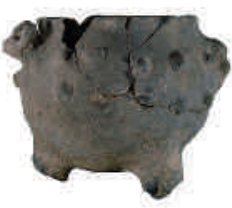

MLP-Ar(n) 10010

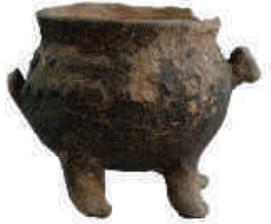

MLP-Ar(n)6469

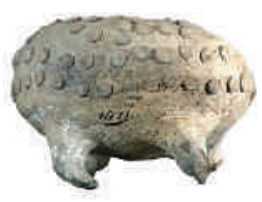

MLP-Ar(n)6971

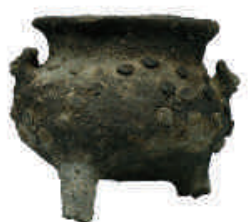

MLP-Ar(n)6357

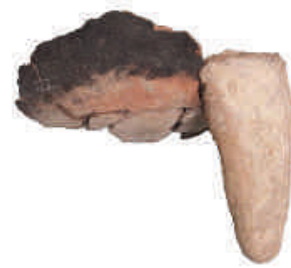

CC 2 Ord B

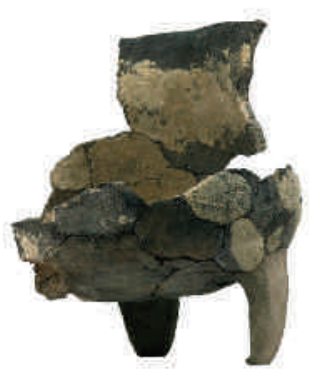

LI 9 Ord B

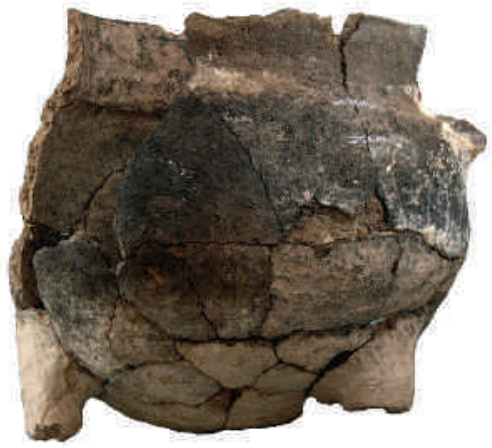

LI 9 Ord A

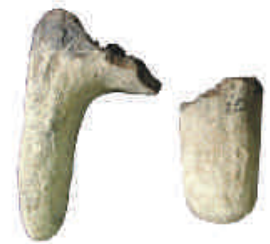

EM 98 Ord E
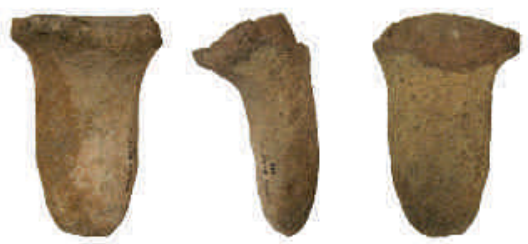

EM Sup Ord 4

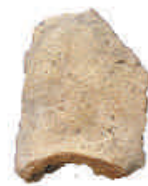

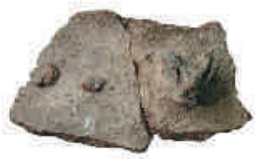

EM 68 Ord K

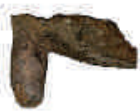

BSur I Ord B

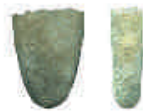

CC 54 Ord B
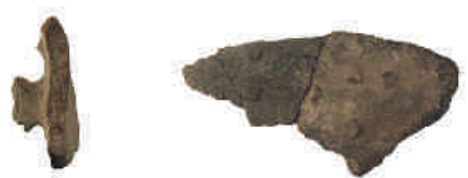

EM 68 Ord J

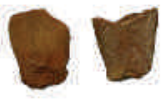

PB Sup Ord A

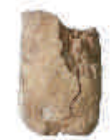

CC 2 Ord C

Figura 2. Muestra de ollas con patas localizadas en el Valle de Hualfín. MLP-Ar(n): piezas pertenecientes a la Colección Benjamín Muñiz Barreto, Museo de La Plata, Facultad de Ciencias Naturales y Museo, Universidad Nacional de La Plata (Argentina), con procedencia funeraria. Piezas reconstruidas y fragmentarias: procedentes de excavadación (nomenclatura con número de estructura) o de superficie (sup) en los sitios CC= Cerro Colorado, LI= Loma de Ichanga, PB= Palo Blanco, EM= El Molino. Figure 2. Sample of footed pots found in the Hualfin Valley. MLP-Ar(n): pieces from the Benjamín Muñiz Barreto collection (Museo de La Plata, Facultad de Ciencias Naturales y Museo, Universidad Nacional de La Plata, Argentina), with funerary origin. Reconstructed and fragmented pieces: excavated (names include the number of the structure) and surface (sup) pieces found at sites: CC =Cerro Colorado, LI=Loma de Ichanga, PB= Palo Blanco, EM= El Molino. 


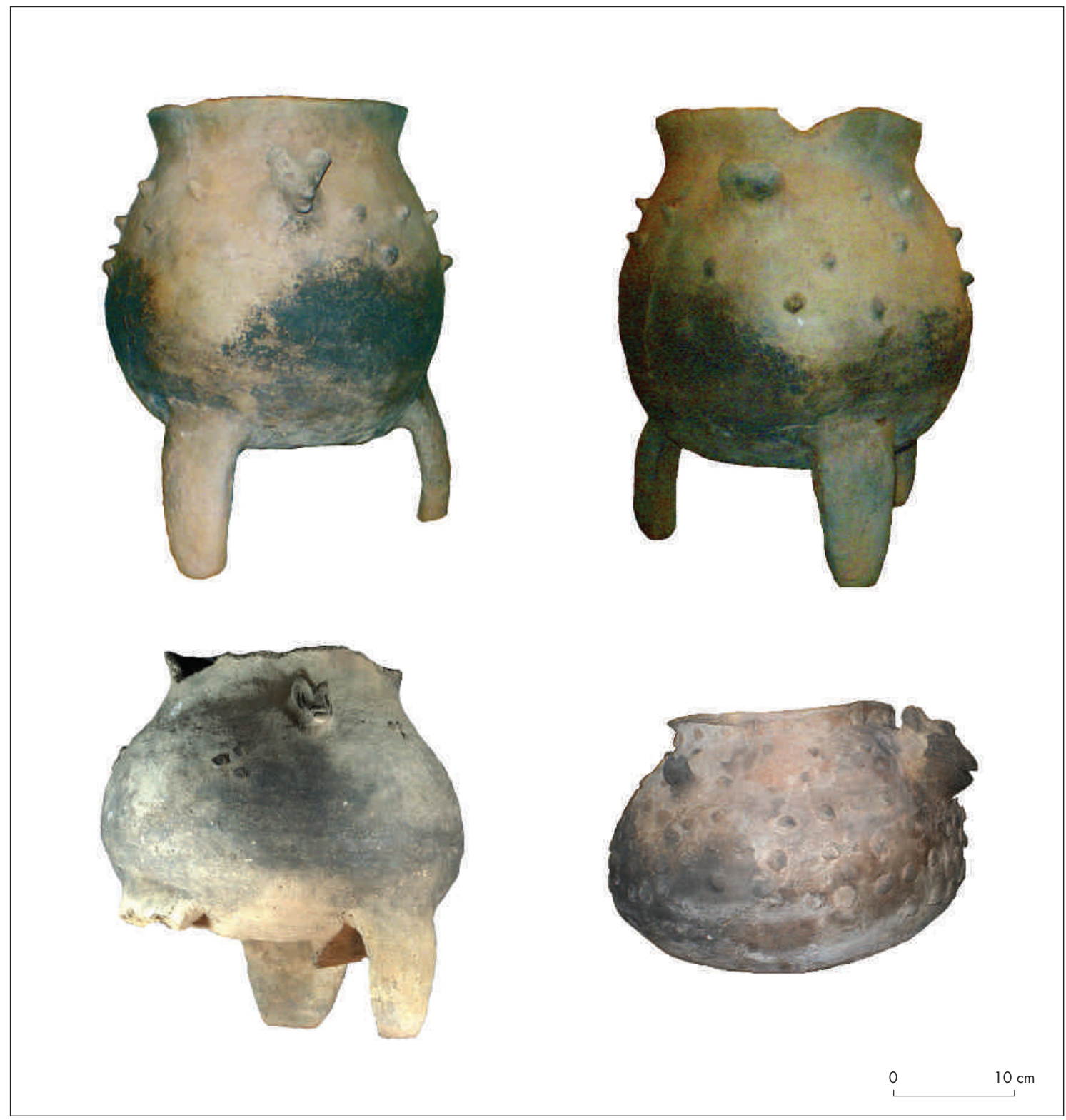

Figura 3. Ejemplos de ollas con patas del Departamento de Belén, sin precisiones sobre su procedencia. Arriba: dos vistas de una pieza expuesta en el Hotel de Belén (Catamarca, Argentina). Abajo izquierda: pieza CH.CC 350, Museo Cóndor Huasi (Belén, Catamarca, Argentina). Abajo derecha: pieza expuesta en el Hotel de Belén. Figure 3. Examples of footed pots from Belén Department with unconfirmed provenance. Above: vessel on display at the Hotel de Belén (Catamarca, Argentina). Top, left: vessel CH.CC 350, Museo Cóndor Huasi (Belén, Catamarca, Argentina). Bottom, right: vessel on display at the Hotel de Belén.

se caracterizan, mayoritariamente, por la presencia de tiesto molido, que puede encontrarse como añadido único o junto con sedimentos de tamaño arena y limo, mientras que en algunas ocasiones se ha observado el uso de sedimentos arenosos de tamaño relativamente grueso. El tiesto molido se encuentra en las vasijas ordinarias de los diversos tamaños y procedencias. En cambio, la cerámica Belén raramente presenta tiesto molido entre sus inclusiones, mientras que las pastas más frecuentes contienen sedimentos arenosos y fragmentos pumíceos en diferente proporción (Zagorodny et al. 2010, Iucci 2013). 
Tabla 2. Registro de ollas con patas sin procedencia conocida o de procedencia externa al Valle de Hualfín. Table 2. Record of footed pots of unknown provenance or found outside of the Hualfin Valley.

\begin{tabular}{|c|c|c|c|c|c|c|}
\hline PIEZA & DEPÓSITO & FUENTE & PROCEDENCIA & $\begin{array}{c}\text { GRADO DE } \\
\text { REPRESENTACIÓN }\end{array}$ & $\begin{array}{c}\text { SECTOR } \\
\text { REPRESENTADO }\end{array}$ & TAMAÑO \\
\hline 22 & $\begin{array}{c}\text { Museo } \\
\text { Arqueológico } \\
\text { Tulio Robaudi } \\
\text { (MATR) }\end{array}$ & $\begin{array}{c}\text { De La } \\
\text { Fuente 2007: } \\
\text { AII } 286\end{array}$ & Tinogasta & $\begin{array}{c}\text { Completa } \\
\text { (faltan patas) }\end{array}$ & Cuerpo y cuello & Mediana \\
\hline MCH 350 & $\begin{array}{l}\text { Museo } \\
\text { Arqueológico } \\
\text { Cóndor } \\
\text { Huasi (Belén, } \\
\text { Catamarca) }\end{array}$ & - & Depto. de Belén & bien representada & Cuerpo y cuello & mediana \\
\hline MCH 517 & $\begin{array}{l}\text { Museo } \\
\text { Arqueológico } \\
\text { Cóndor } \\
\text { Huasi (Belén, } \\
\text { Catamarca) }\end{array}$ & - & Depto. de Belén & completa & completa & muy chica \\
\hline - & - & Puente 2012 & Valle del Bolsón & fragmento & pata & muy chica \\
\hline- & - & Puente 2012 & Valle del Bolsón & fragmento & pata & mediana (?) \\
\hline $\begin{array}{l}\text { MLP-Ar(n) } \\
\quad 5323\end{array}$ & Museo de La Plata & $\begin{array}{c}\text { Palamarczuk } \\
2009\end{array}$ & Famabalasto & completa & completa & muy chica \\
\hline- & - & $\begin{array}{l}\text { Serrano } \\
1958 \text { Lam. } \\
\text { xxVII }\end{array}$ & Fuerte Quemado & completa & completa & muy chica \\
\hline- & Hotel Belén & - & - & completa & completa & mediana \\
\hline- & Hotel Belén & - & - & completa & completa & chica (?) \\
\hline
\end{tabular}

Tabla 3. Rango de medidas y volúmenes por clase de tamaño de la cerámica ordinaria procedente del Valle de Hualfín. Table 3. Range of dimension and volume of non painted and rugged wares ceramics from Hualfin Valley, classified by size.

\begin{tabular}{c|c|c|c|c|c} 
TAMAÑ & $\begin{array}{c}\text { ALTURA } \\
\text { TOTAL } \\
(\mathrm{cm})\end{array}$ & $\begin{array}{c}\text { DIÁMETRO } \\
\text { ABERTURA } \\
(\mathrm{cm})\end{array}$ & $\begin{array}{c}\text { DIÁMETRO } \\
\text { MÁXIMO } \\
(\mathrm{cm})\end{array}$ & $\begin{array}{c}\text { RANGO DE } \\
\text { VOLUMEN EN } \\
\text { PIEZAS (litros) }\end{array}$ & $\begin{array}{c}\text { CATEGORIA } \\
\text { DE VOLUMEN }\end{array}$ \\
\hline Muy chicas & $6,5-11,4$ & $3,5-8$ & $8,6-13,3$ & 0,66 & 1 litro \\
\hline Chicas & $15,9-19,6$ & $8,1-19,2$ & $21,3-17$ & $1,16-3,92$ & entre 1 y 5 litros \\
\hline Medianas & $14,6-30,4$ & $15,3-30,4$ & $29-38,3$ & $5,30-14,78$ & entre 5 y 15 litros \\
\hline Grandes & $39,7-61$ & $28,4-44,8$ & $40,3-52$ & $38,23-80,51$ & más de 35 litros
\end{tabular}




\section{CERÁMICA ORDINARIA}

Diámetro máximo / Altura máxima ( $\mathrm{N}=26)$

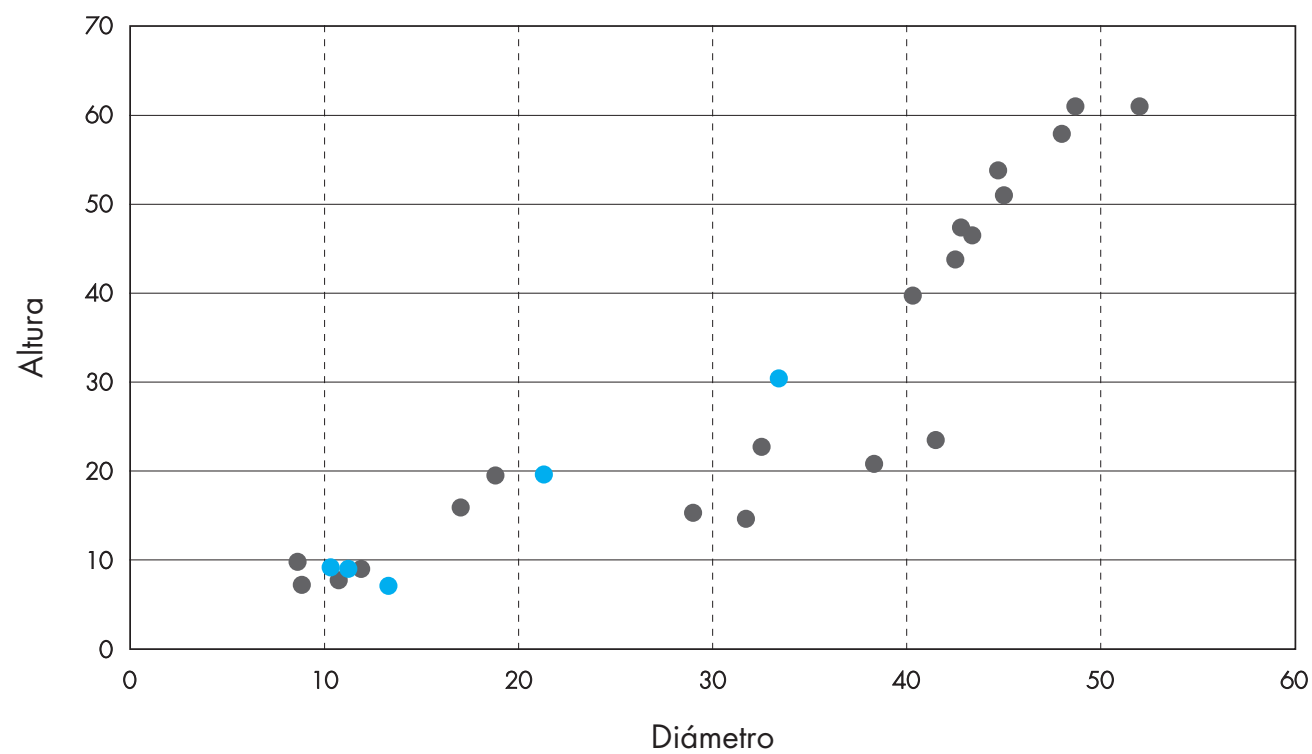

\section{CERÁMICA ORDINARIA}

Diámetro máximo / Altura máxima ( $\mathrm{N}=26)$

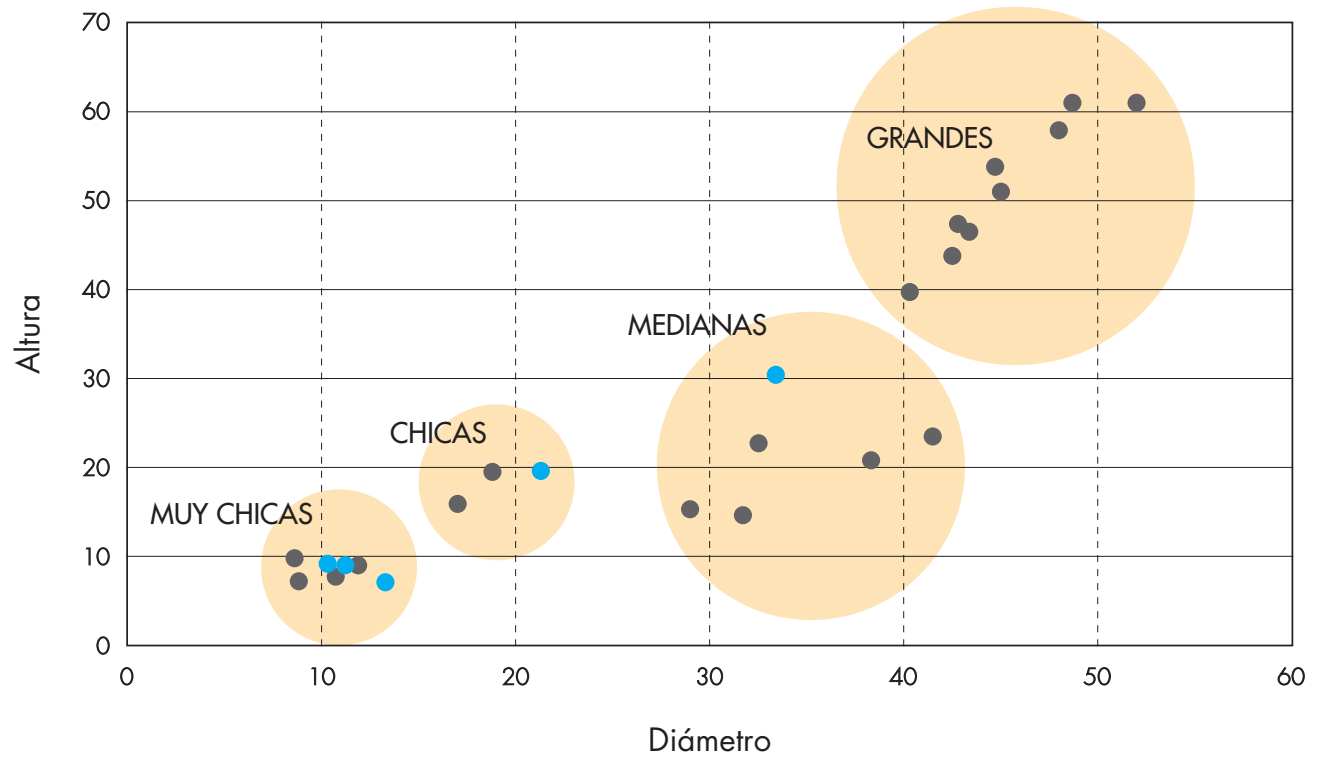

- Ollas con patas

- Ollas sin patas

Figura 4. Distribución de tamaños de un conjunto de vasijas ordinarias enteras y bien representadas procedentes del Valle de Hualfín. Figure 4. Size distribution of a set of non painted and rugged wares and well represented pots from the Hualfin Valley. 


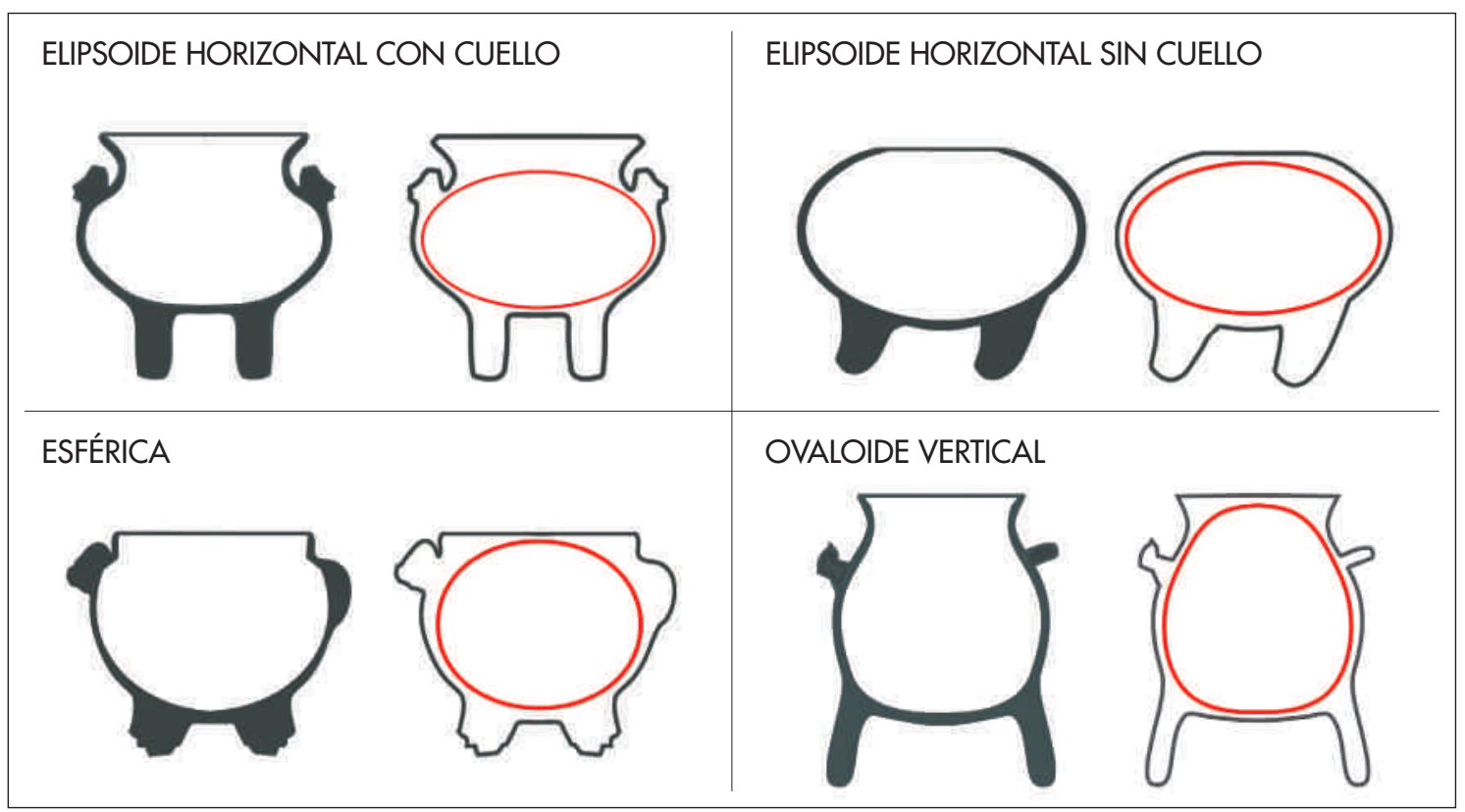

Figura 5. Principales morfologías del cuerpo de las ollas con patas de la muestra con procedencia conocida en el valle. Figure 5. Main body morphologies of footed pots of known provenance in the valley.

En base a una muestra de piezas ordinarias completas y bien representadas en las que se pudo medir el diámetro de abertura, el diámetro máximo y la altura, se logró obtener una clasificación por tamaños (fig. 4) y un cálculo de la capacidad en litros del conjunto (Tabla 3).

Entre las ollas con patas mejor representadas en la muestra se pudieron identificar tres morfologías principales para el cuerpo (fig. 5): elipsoide, con su eje mayor dispuesto horizontalmente, esférica y ovaloide, con su eje mayor dispuesto verticalmente; y se analizaron los puntos más significativos para la toma de dimensiones (fig. 6, Tabla 4). La primera forma puede o no tener cuello, mientras que las otras poseen un cuello vertical o evertido. En la clasificación de tamaños del conjunto ordinario, este grupo se distribuye en las categorías muy chicas, chicas y medianas (fig. 4).

El cuerpo está sostenido por tres o cuatro apéndices alargados o "patas", ubicados en su base. Elegimos la denominación de "pata" para este elemento para distinguirlo del "pie", término con el que nos referimos a un soporte único, colocado en el eje central de la vasija, de muy alta frecuencia entre la cerámica ordinaria tardía de la zona.

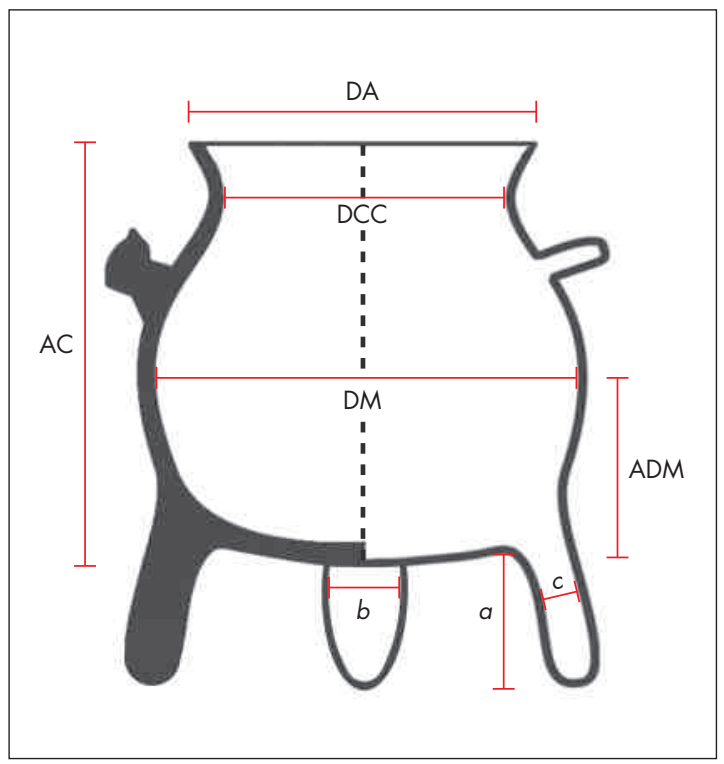

Figura 6. Puntos de referencia para la toma de medidas de las ollas con patas. $\mathrm{AC}=$ altura del cuerpo, $\mathrm{DA}=$ diámetro de abertura, DCC= diámetro de la constricción del cuello, DM= diámetro máximo, $\mathrm{ADM}=$ altura del diámetro máximo, a, b y c= ejes de toma de medidas de las patas. Figure 6. Reference points for measuring footed pots. $A C=$ body height, $D A=$ maximum diameter, $A D M=$ height of maximum diameter, $a, b$, and $c=$ axes for leg measurements. 
Tabla 4. Registro de medidas de la muestra de ollas con patas del Valle de Hualfín y de otras procedencias con medidas conocidas. Table 4. Record of measurements for the sample of footed pots from the Hualfín Valley and other known provenances.

\begin{tabular}{|c|c|c|c|c|c|c|c|c|c|c|c|}
\hline EJE C & DA & $\mathrm{AT}$ & $\mathrm{AC}$ & $\mathrm{DM}$ & $\mathrm{ADM}$ & DCC & $\mathrm{ACC}$ & $\mathrm{GC}$ & EJE A & EJE B & EJE C \\
\hline EM 68 Ord J & - & - & & - & & - & - & 0.65 & - & - & - \\
\hline EM 68 Ord K & - & - & - & - & - & - & - & - & - & - & - \\
\hline EM 98 Ord E & - & - & - & - & - & - & - & - & 8.58 & 4.3 & 2.82 \\
\hline EM S Ord 4 & - & - & & - & & - & - & - & 11.5 & 5.3 & 4.7 \\
\hline PB S Ord 2 & - & - & & - & & - & - & - & - & - & - \\
\hline CC2 Ord B & - & - & & - & & - & - & 1.2 & 11.5 & 6 & 2.3 \\
\hline CC 2 Ord C & - & - & & - & & - & - & - & - & - & - \\
\hline CC 54 Ord B & - & - & & - & & - & - & - & - & - & - \\
\hline BS1 Ord A & - & - & & - & & - & - & - & 2.3 & 1.9 & 1.5 \\
\hline LI 9 Ord A & 25.7 & - & 30.4 & 33.4 & 15.35 & 25.2 & 3.8 & 0.85 & - & - & - \\
\hline LI 9 Ord B & 19.2 & 24.25 & 19.6 & 21.3 & 7.4 & 16.7 & 5.9 & 0.95 & 5 & 4.5 & 1.3 \\
\hline MLP-Ar(n) 10010 & 9.3 & - & 9 & 11.5 & 5.1 & 9.1 & 1.1 & 0.65 & - & - & - \\
\hline MLP-Ar(n) 6971 & 8.5 & 9.07 & 7.1 & 13.3 & 3.98 & - & - & 0.6 & 2.8 & 2.15 & 1.8 \\
\hline MLP-Ar(n) 6357 & 8 & - & 6.5 & 9 & 3.32 & 6.6 & 1.4 & 0.6 & - & - & - \\
\hline MLP-Ar(n) 6469 & 10.2 & 11.4 & 8.52 & 11.1 & 4.09 & 9.4 & 1.5 & 0.65 & 2.6 & 1.7 & 1.7 \\
\hline
\end{tabular}

\section{Identificación de marcas y reconocimiento de atractores}

Dado que en nuestro caso la imagen y sus marcas se representan en tres dimensiones, para aislar y registrar las unidades apelamos a la proyección ortogonal, un tipo de proyección centrada más en el objeto que en el observador (Willats 1994), tomando los puntos de vista necesarios para describir la imagen, y recuperando, así, las formas permanentes de los objetos, tanto en el dibujo como en la fotografía.

Las marcas identificadas son modeladas e incisas, y su número en todo el conjunto es pequeño (fig. 7). Pueden conformar atractores al combinarse en un único sector del cuerpo de la vasija, por ejemplo, una cabeza; o en diferentes sectores, para configurar por entero la vasija zoomorfa. Las particularidades de las marcas y su distribución en la pieza cerámica son herramientas para reconocer el referente y algunas pautas de su comportamiento.
El atractor cabeza tiene formas que varían de triangular a redondeada, y puede estar muy bien definido o apenas esbozado (fig. 8). En la mayoría se identifican orejas y hocico modelados, narinas y ojos realizados con incisiones de punto simple o rectas, $y$ boca modelada o incisa.

El atractor cola se reconoce más por la posición de las marcas en el cuerpo de la vasija que por sus características morfológicas (fig. 8). Nos referimos a marcas que se encuentran en el sector ecuatorial de la vasija o por encima de éste, ubicadas en el lado opuesto a la cabeza, y que morfológicamente son pequeños cilindros, cilindros partidos, medios discos de arcilla y conos. Una pieza ilustrada por Serrano (1958: Lám. xxviI), de la que puede observarse un solo lado, muestra una aplicación modelada en forma de herradura que podría interpretarse también como una cola.

Los elementos adheridos al cuerpo consisten en pequeños discos y conos de arcilla. En una de las piezas procedentes de una zona cercana al área 


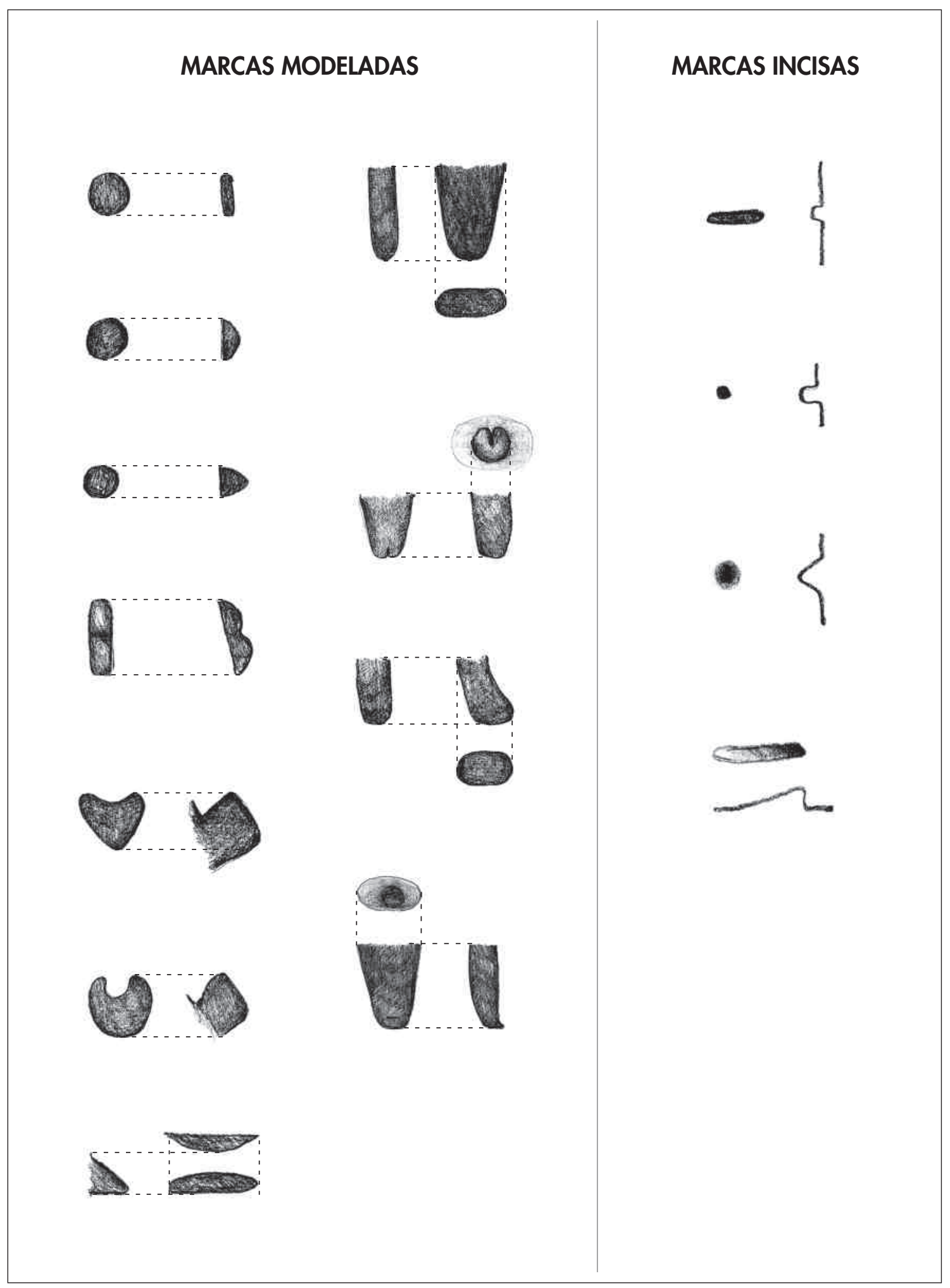

Figura 7. Repertorio de marcas identificadas en la muestra. Figure 7. Repertoire of marks identified among the sample. 

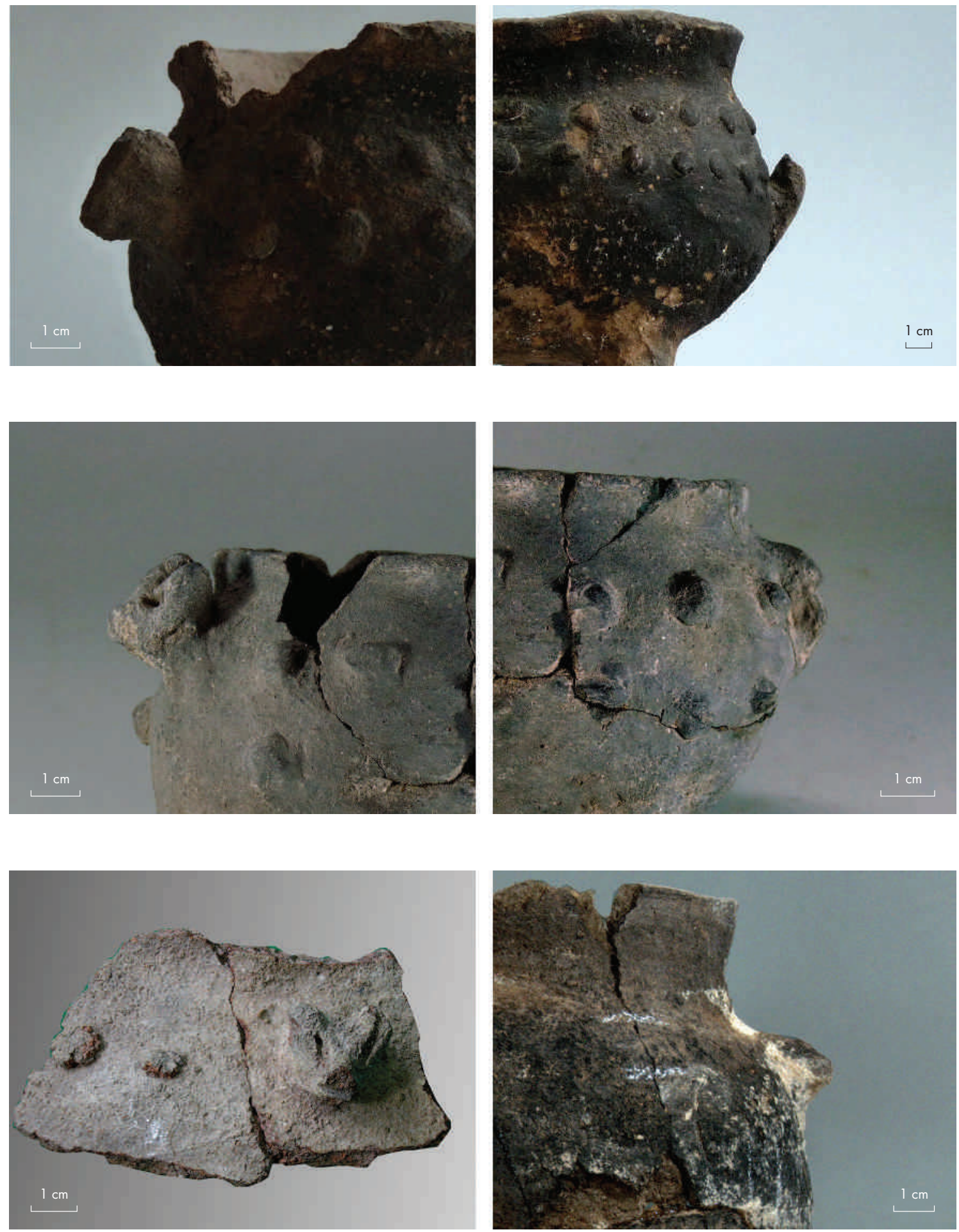

Figura 8. Algunos de los atractores reconocidos para las ollas con patas del Valle de Hualfín: cabezas y colas. Arriba: cabeza y cola de vasija MLP-Ar(n) 6469, centro: cabeza y cola de vasija MLP-Ar(n) 10010, abajo izquierda: cabeza de pieza EM 68 Ord K, derecha: cola de pieza LI 9 Ord A. Figure 8. Selected atractores identified on footed pots of the Hualfin Valley: heads and tails. Above: head and tail of the MLP$\operatorname{Ar}(n) 6469$ vessel, center: head and tail of MLP-Ar(n) 10010 vessel; left bottom: head of EM 68 Ord K vessel, right: tail of LI 9 Ord A vessel. 

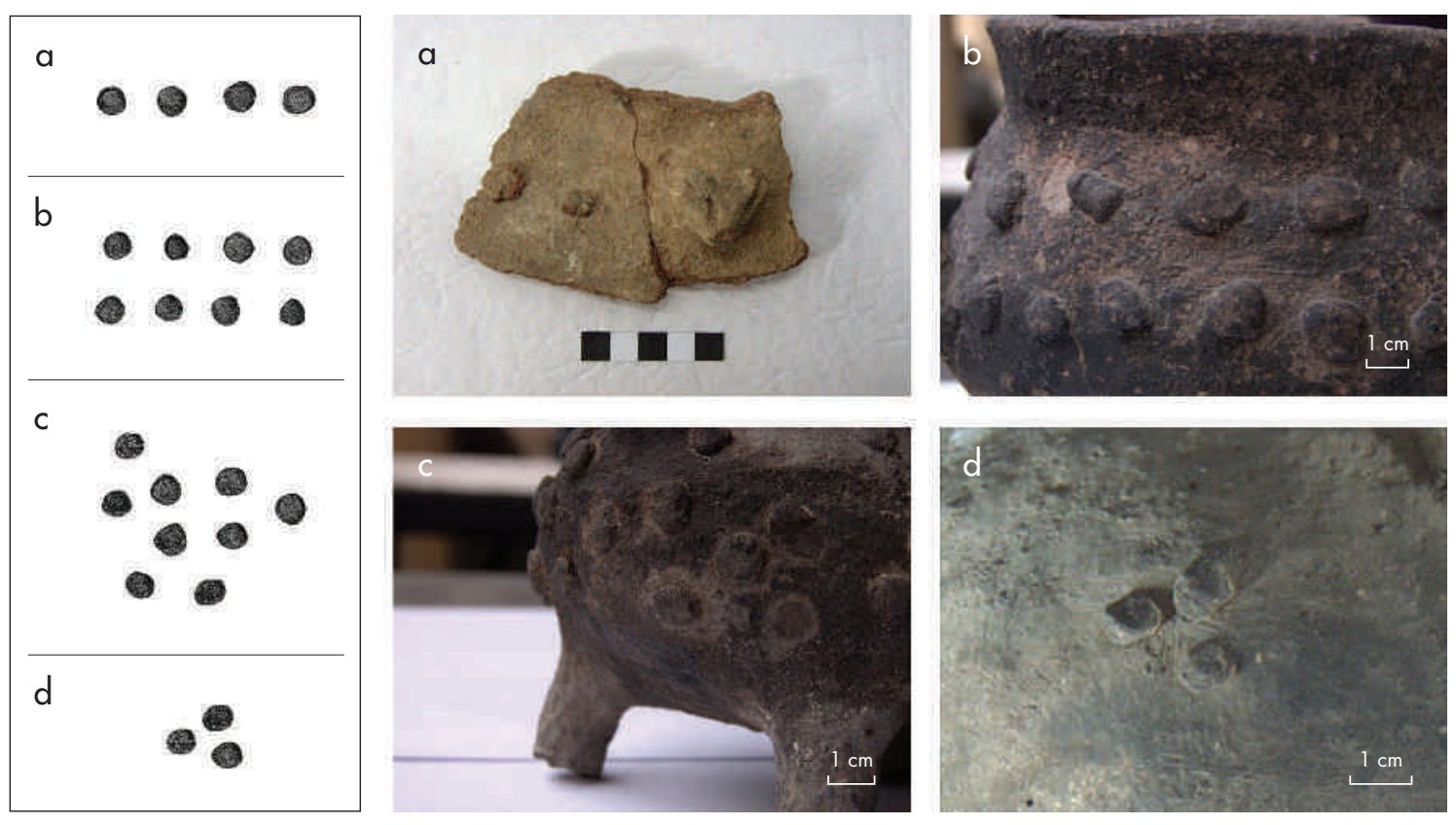

Figura 9: Tipos de disposición de los discos modelados adheridos al cuerpo (izquierda) y ejemplos en las piezas, a= EM 68 Ord K, distribución en línea; b= MLP-Ar(n) 6469, distribución en doble línea; c= MLP-Ar(n) 6357, al azar y c= CH.CC 350, en tríadas. Figure 9. Arrangements of molded discs attached to the body (left) and examples in other pieces, $a=E M 68$ Ord K, single line; $b=M L P-A r(n) 6469=$ double line; $c=M L P-A r(n)$ 6357, random and $c=$ CH.CC 350, triads.

estudiada, en la localidad de Famabalasto, son ojos en forma de grano de café (pieza MLP-Ar(n) 5323; en Palamarczuk 2009: Apéndice III: Lámina 31). Pueden estar distribuidos azarosamente, ordenados en líneas o presentados en tríadas, ocupando solo un sector o todo el cuerpo (fig. 9).

Las patas pueden ser de corte horizontal, circular $\mathrm{u}$ oval, y de perfil longitudinal aproximadamente rectangular, ovaloide o triangular. Pueden tener el sector de apoyo modelado, con una curvatura, una escotadura o una incisión. Se encuentran en número de tres o cuatro, siempre colocadas en la base del cuerpo de la vasija. En una misma pieza se presentan con posiciones regulares $o$ algo variables en cuanto al ángulo con el cuerpo, y en algunos casos tienen un sutil doblez (fig. 10).

\section{De la imagen modelada al referente}

Desde una mirada de conjunto estas vasijas tienen un aspecto claramente zoomorfo, se reconoce un animal de pie, con cabeza, patas y cola. La incisión o escotadura en la base de las patas puede interpretarse como la representación de una pezuña de artiodáctilo, mientras que los discos y conos aplicados en el cuerpo podrían corresponder al pelo del animal. A partir de estos detalles, nuestra propuesta interpretativa es que estas ollas remiten a camélidos.

Entre la cerámica del Noroeste de Argentina, la representación de camélidos se destaca principalmente en la alfarería Ciénaga (Serrano 1958; González 1972; Balesta 2000, 2015), que fue manufacturada por poblaciones que habitaron la región valliserrana, y en particular el Valle de Hualfín, durante la primera mitad del primer milenio de la era. En la alfarería más tardía, los camélidos pierden ese protagonismo (González 1974). No obstante, se identifican ocasionalmente en las imágenes pintadas de algunas vasijas, como por ejemplo en una tinaja Belén registrada en el Museo Lillo de Tucumán (Quiroga \& Puente 2007), o en un puco Belén procedente de la localidad de El Eje (fig. 11). También se encuentran mamelones modelados con figuras semejantes a camélidos en el cuerpo superior de las tinajas Belén, aunque en estos casos la interpretación no es clara. Por otra parte, en la Quebrada de Humahuaca, en el sitio Doncellas y en otros sectores de la Provincia de Jujuy (Argentina), se registraron para la época tardía una serie de vasijas 

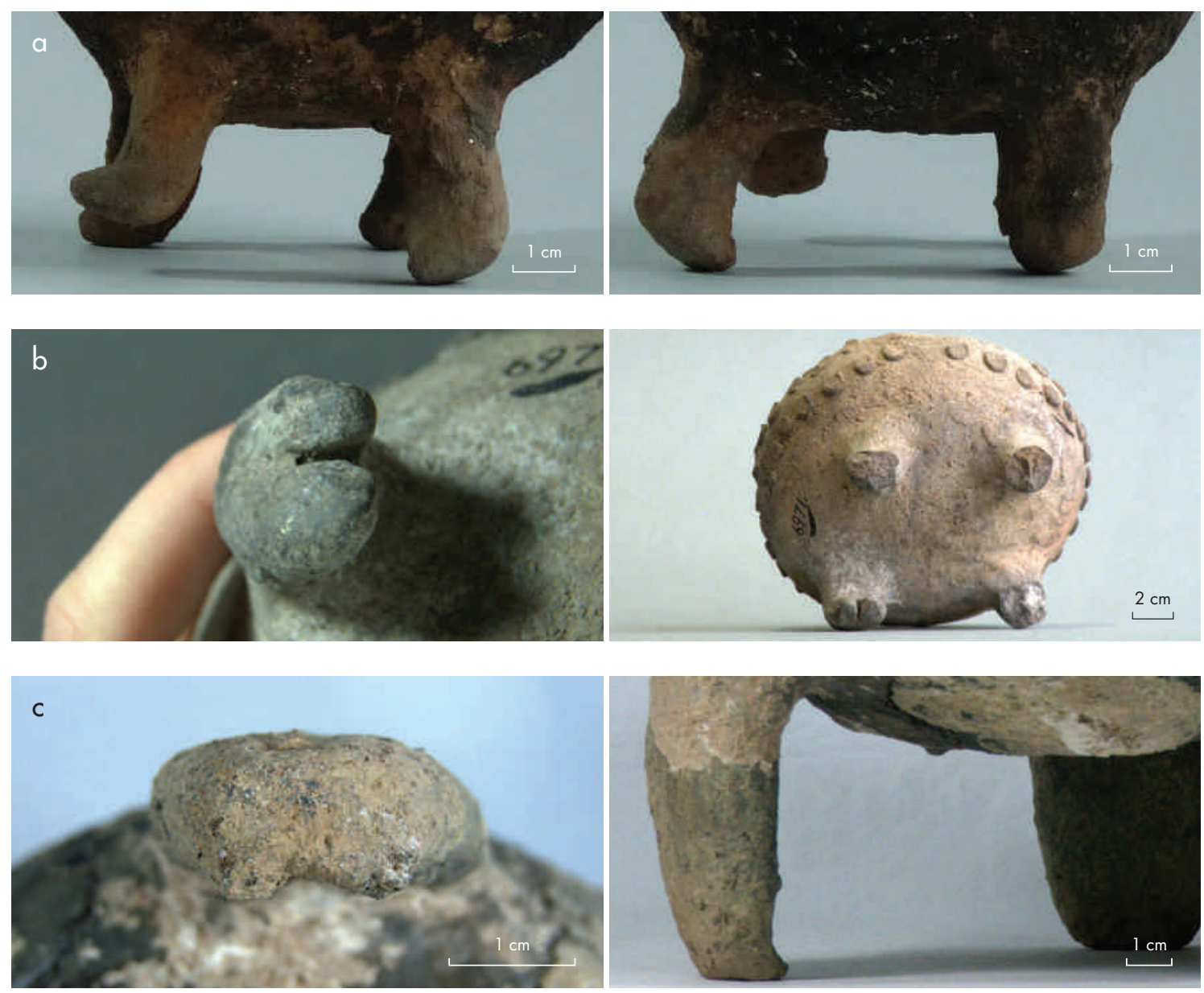

Figura 10. Ejemplos de patas. $\mathrm{a}=\mathrm{MLP}-\operatorname{Ar}(\mathrm{n}) 6479, \mathrm{~b}=\mathrm{MLP}-\operatorname{Ar}(\mathrm{n}) 6971, \mathrm{c}=\mathrm{LI} 9$ Ord B. Figure 10. Examples offeet. $a=M L P-A r(n) 6479$, $b=\operatorname{MLP}-\operatorname{Ar}(n) 6971, c=L I 9$ Ord B.

zoomorfas modeladas conocidas como chuiayuros, que representan llamas (Pérez \& Velázquez Cabrera 2015, Zaburlin 2016, entre otros) y tienen continuidad en el uso hasta la actualidad (Menacho 2007).

La relevancia de los camélidos como participantes de la cultura de las sociedades del Noroeste Argentino es insoslayable, y para la época tardía se plantea su consumo como recurso alimenticio, el uso de productos secundarios como la lana, la existencia de prácticas de cría, caza y tráfico caravanero, y una multiplicidad de relaciones que median entre las personas y estos animales (Madero 1993-1994, Moreno \& Revuelta 2010, Mercolli 2011, Grant \& Escola 2015, entre otros). La información para las poblaciones tardías del Valle de Hualfín sostiene la presencia del taxón entre los restos esqueletales identificados en las excavaciones, la exis- tencia de contextos de consumo de carne de camélidos (Lorenzo 2017, Lorenzo \& Del Papa 2018) y evidencias de hilado y tejido en la materialidad ligada a la funebria, entre las que se encuentran hebras de lana (Wynveldt 2009). De este modo, y haciendo la salvedad de que pueden encontrarse referencias a los camélidos en el arte rupestre de la zona, que es un campo aún poco explorado, es llamativa su escasa presencia entre las manifestaciones cerámicas tardías más conocidas en la literatura arqueológica. En este sentido, creemos que es válido sostener que las figuras representadas en las ollas con patas corresponden a camélidos.

Una vez asumida esta posibilidad de representación, pueden reconocerse particularidades en cada uno de los ejemplares cerámicos. Por un lado, entre la serie de pequeño tamaño, encontramos el mayor grado 
de naturalismo, expresado en la pieza MLP-Ar(n)6469 (fig. 2). Todas las partes del cuerpo identificadas para el conjunto están presentes: la cabeza, cuatro patas y la cola, que apunta hacia arriba (fig. 8), posición registrada en los camélidos pintados en la vasija Belén mencionada por Quiroga y Puente (2007) de la colección Schreiter (pieza MA0261, Museo del Instituto de Arqueología y Museo, Universidad Nacional de Tucumán) -además, en esta vasija pueden observarse puntos pintados en negro que rellenan el cuerpo, que podrían ser análogos a los discos modelados en el cuerpo de las ollas con patas-. Por su parte, los extremos de las patas de la vasija 6469 no tienen incisión, pero esbozan una curvatura, a modo de sector de apoyo. La sensación de que el animal está en movimiento está dada por la falta de simetría en sus posiciones.

En las otras piezas muy chicas no están presentes todos los rasgos constitutivos del animal: no tienen una pata o la cabeza y la cola. Una de ellas (MLP-Ar(n)6357) tiene dos cabezas, ubicadas en lados opuestos, y no lleva cola, y otra (MLP-Ar(n)10010) no tiene cabeza, mientras que las patas son tres.

La única vasija de tamaño chico no tiene, entre la porción reconstruida del cuerpo, ningún elemento añadido. Las patas son tres, algo curvas, con la zona de apoyo modelada y con una incisión apenas esbozada (pieza LI 9 Ord B, fig. 2).

Las vasijas medianas tienen tres patas. A una (LI 9 Ord A, fig.2) se le añadió solo una cola, mientras que a otras dos (fig. 3) se les suman una o dos cabezas, colas, conos y discos en tríadas. Una exhibe, en lugar de cabeza, un modelado más complejo que presenta similitudes con algunas de las figuras incorporadas a la cerámica Belén sobre las asas en el cuerpo superior.

En el conjunto de piezas se destaca una que no tiene patas como soporte de la vasija, y presenta dos pequeños apéndices en la parte superior del cuerpo (fig. 3). Tiene dos cabezas, una de mayor tamaño que la otra, que no se encuentran en posición opuesta como en otras observadas sino contigua. Más allá de la ausencia de un elemento morfológico estructural como las patas, la idea de pertenencia al grupo está dada por la presencia de las marcas y atractores correspondientes al cuerpo. Para la interpretación de la imagen en su conjunto cabría considerar, a modo de hipótesis, que representa dos camélidos echados, probablemente un adulto y su cría -representación registrada por Zaburlín (2016) para el conjunto zoomorfo de la puna jujeña-.
En síntesis, una vez identificado el repertorio de marcas en una serie de vasijas, reconocidos los atractores y el referente posible al que alude la imagen, no es necesario volver a enfrentarse a una pieza en la que todos los atractores se encuentren presentes para poder interpretar la referencia. A partir de algunos elementos puede activarse el proceso de reconocimiento e identificarse la figura de un camélido.

\section{Adecuaciones para las funciones mecánicas y huellas de uso}

Además de configurarse como un tipo particular de signo, estas vasijas tienen una participación en el ámbito de la práctica como contenedores, aspecto que lleva a que la imagen pueda ser interpretada en la interrelación con otras semiosis vigentes. La cuestión de las adecuaciones para el uso cerámico implica que en las tradiciones de manufactura los alfareros comprometen saberes, ensayos, aprendizajes y observaciones relacionados no solo con la cadena operativa sino también con las prácticas en las que estarán involucradas las vasijas. Así, en el proceso de diseño y en las diferentes etapas de la producción, entre muchas otras consideraciones posibles, probablemente se contemplan cuestiones como el desempeño de los objetos terminados y las propiedades físicas de las vasijas, que posibilitan, facilitan o restringen usos concretos (Rice 1987, Menacho 2007).

En este sentido, la práctica alfarera misma tiene esa capacidad de observación y conocimiento empírico acerca de algunos resultados, que pueden influir en el proceso de toma de decisiones de la manufactura. Por otro lado, en este proceso también confluyen gustos, percepciones y preferencias de otros actores, quienes eligen ya sea las piezas cerámicas manufacturadas, o a los alfareros para que produzcan vasijas con ciertas características (Costin 2001, Sillar \& Tite 2000, Roux 2003). Las decisiones, en su conjunto, no son al azar ni responden exclusivamente a preferencias individuales, sino que son parte constitutiva del orden social (Sillar \& Tite 2000). Más allá de estas observaciones, tal como señala Gastaldi (2010), los usos de las vasijas están dados y adquieren sentidos, en definitiva, en la práctica misma, a través de las conexiones de distinto alcance con otras agencias involucradas en el transcurso de sus trayectorias. De este modo, lo desarrollado aquí es solo una línea de aproximación a una red de relaciones posibles. 


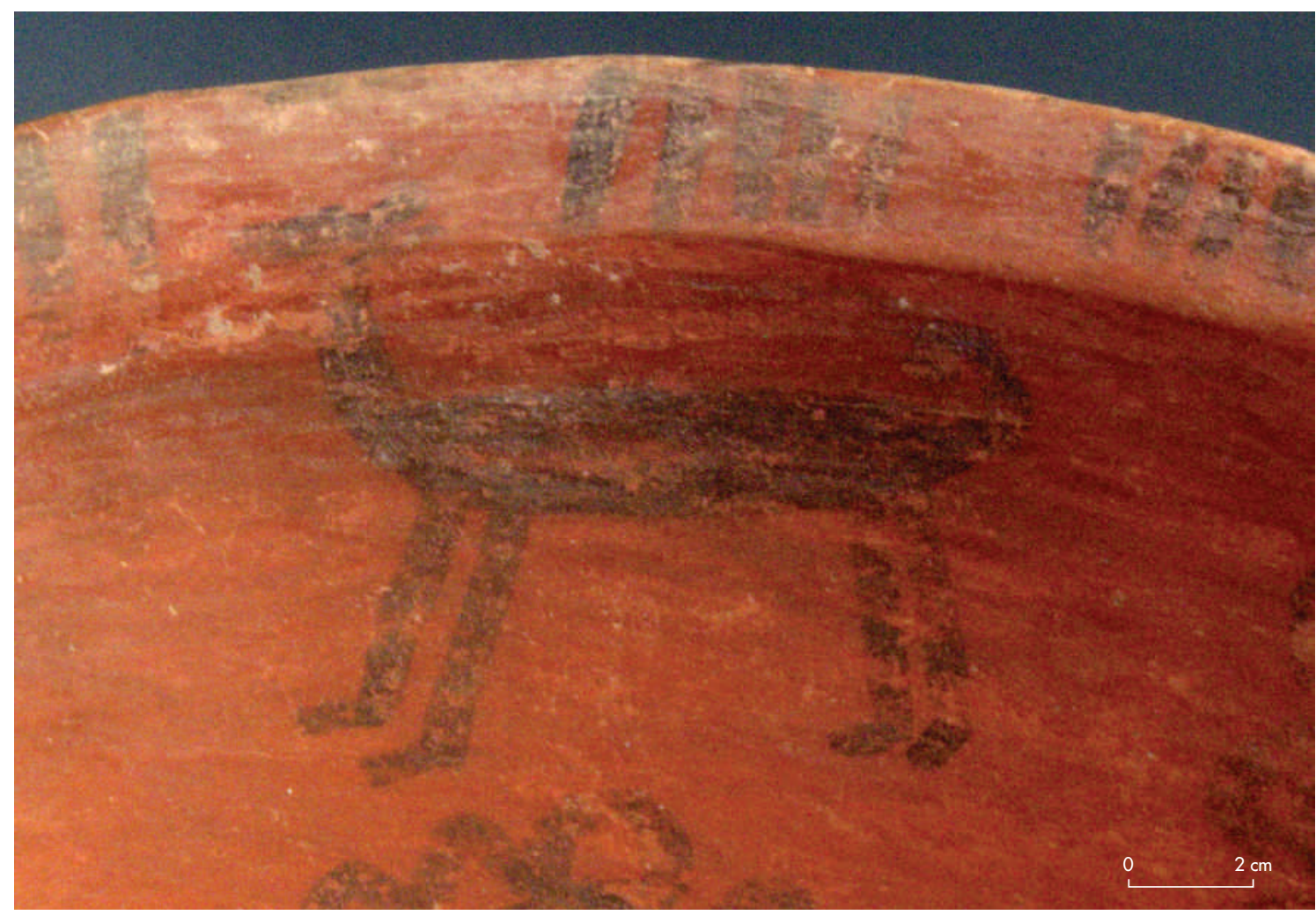

Figura 11. Puco Belén hallado en la localidad de El Eje con una posible representación de camélidos. Figure 11. Belen Bowl from El Eje with a possible representation of a camelid.

Desde este punto de vista, con respecto a las cualidades morfológicas de performance, estas vasijas son estables y resistentes al volcado, presentan constricciones en la abertura que contribuyen a disminuir posibles derrames, y las patas le dan una distancia en relación a una fuente de calor que evita el calentamiento repentino o directo. El diseño morfológico, de este modo, es adecuado para calentar líquidos y otras sustancias sobre camas de carbón. Considerando la diversidad de tamaños, el conjunto tiene capacidades para diferentes cantidades de contenido.

La exposición a una fuente de calor está evidenciada por la principal huella de uso efectivo, que es la acumulación de hollín. Esta acumulación es el producto de la combustión de material orgánico y del depósito de la materia carbonizada resultante sobre o dentro de las paredes cerámicas porosas y permeables, generalmente con patrones característicos (Skibo 1992). Los depósitos pueden relacionarse con la exposición de las vasijas al fuego abierto para calentar los contenidos, durante la cual la combustión produce el material quemado que no es absorbido por las paredes externas. Del lado interno, por lo general son originados por la carbonización de la materia orgánica introducida-como por ejemplo restos de comida-, proceso que es acumulativo y lleva a que el hollín penetre y que no sea removido con el lavado.

Todas las ollas con patas enteras y bien representadas exhiben depósitos de hollín. Entre los depósitos externos se identificaron cuatro patrones básicos (fig. 12) según la densidad de la acumulación en cada zona (Iucci 2013). Todas las modalidades indican que las piezas fueron expuestas a fuentes de calor de diferente intensidad durante eventos reiterados. En líneas generales, las patas o parte de ellas no presentan acumulaciones densas, y su aspecto es entre blanquecino y levemente grisáceo, un elemento indicador de la exposición directa al calor en varias ocasiones. El conjunto indica que las vasijas de todos los tamaños eran colocadas sobre fuegos abiertos o camas de carbón, y la llama podía llegar hasta la zona inferior del cuerpo, dado que hacia la porción media en general los depósitos se encuentran bien delimitados. 
En cuanto al interior, se observan acumulaciones de carbón de distinta intensidad que ocupan la mayor parte de las superficies. En general se encuentran de manera uniforme en todo el espesor de la pared, pero en algunos casos pudo registrarse una zonificación entre la zona media y el fondo, como por ejemplo en la pieza MLP-Ar(n) 6469 (fig. 2), mientras que en la vasija Li 9 Ord A (fig. 2) la zonificación se encuentra reducida al fondo del recipiente, conformando una acumulación densa que penetra más de la mitad de la pared y que puede asociarse con el tostado o quema reiterada de un contenido.

Por otra parte, cabe considerar otras posibilidades respecto del origen del hollín, como por ejemplo la combustión de techos. De hecho, en las estructuras arqueológicas del valle se registraron este tipo de fenómenos, y el consecuente depósito de hollín sobre el material cerámico situado en el piso (Iucci 2013). Este tipo de evento fue registrado solo en uno de los contextos de procedencia de las ollas con patas, pero no lo asociamos a los patrones de distribución del hollín. En este sentido, atribuimos el ennegrecimiento de estas vasijas únicamente a su asociación con fogones para calentar contenidos.

Además de los depósitos de hollín, con frecuencia también se presentan roturas y el desprendimiento de las aplicaciones modeladas. Estos tipos de modificaciones en la integridad de las piezas pueden relacionarse con actividades de uso y con las manipulaciones frecuentes a las que podrían verse expuestas, pero se dan justamente en los puntos de mayor esfuerzo de las vasijas, como las patas, o en los sectores en los que el único mecanismo de fijación fue la adherencia -y que, por lo tanto, son puntos frágiles del cuerpo cerámico-, como los discos. En cambio, al igual que gran parte de las piezas del resto del conjunto ordinario, no se registra una presencia importante de huellas de abrasión más finas -definidas como aquellas formadas por remoción o deformación de material por el contacto mecánico con un abrasivo, como el deslizamiento, raspado o golpeteo (Skibo 1992)-. Esta escasez se contrapone con lo que es posible observar entre las piezas Belén, cuyas superficies alisadas y pulidas de todo el cuerpo y de las zonas de apoyo exhiben abundantes huellas de desgaste (Iucci 2013). El efecto de los acabados de superficie rugosos, junto con las características de la microestructura de las pastas, dadas por la presencia de tiesto molido u otros sedimentos de grano relativamente grueso, y una parti- cular abundancia en la cantidad de cavidades, debieron haber incidido positivamente en la resistencia mecánica para usos reiterados o prolongados en el tiempo.

\section{Ámbitos de participación y cronología en el contexto local}

Los asentamientos tardíos del Valle de Hualfín se ubican sobre lomadas de diferentes alturas con una notable visibilidad, poseen diversos grados de aglomeración -desde unas pocas hasta alrededor de cien estructuras- y habituales obras de defensa y barreras para el acceso, coherentes con la caracterización de un paisaje de conflictos (Balesta et al. 2011). En general, los restos de las estructuras arquitectónicas son de piedra, y las viviendas están aisladas o forman grupos de unos pocos recintos. También se registran sitios asociados a tareas agrícolas en los que puede haber o no estructuras de vivienda entre los campos de cultivo, así como recintos aislados en las terrazas de inundación más bajas y barrancas cercanas a los cauces de los ríos. Además de la abundante cerámica Belén y ordinaria que se encuentra en todos los sitios, otros tipos de cerámica tardía, como Santa María, Famabalasto Negro Grabado y Sanagasta, probablemente confeccionadas fuera del valle o por parte de alfareros foráneos, comparten los diferentes contextos de hallazgo, aunque con una distribución desigual dentro del área del valle (Wynveldt 2009, Balesta et al. 2011, Iucci 2013).

En los pisos de las estructuras excavadas se registran habitualmente restos de maíz y en menor medida de otras semillas, y restos de animales, mayoritariamente de camélidos, interpretados en general como producto del consumo de alimentos. La obsidiana, procedente de la puna, se encuentra en todos los sitios, y fue utilizada para la confección de una variedad de artefactos, entre ellos, pequeñas puntas de proyectil apedunculadas (Wynveldt \& Flores, 2014). Las estructuras destinadas a entierros pueden hallarse dentro de los poblados, ocasionalmente en espacios cerrados, y dispersas o formando agrupaciones en el campo. Los tipos más frecuentes son cistas para los adultos y contenedores cerámicos, generalmente Belén y ordinarios tapados con cuencos de cerámica, dispuestos directamente en el sustrato en el caso de los infantes.

Las ollas con patas fueron halladas en el sitio Cerro Colorado, uno de los de mayor envergadura del valle, con más de 100 estructuras arqueológicas. En el 


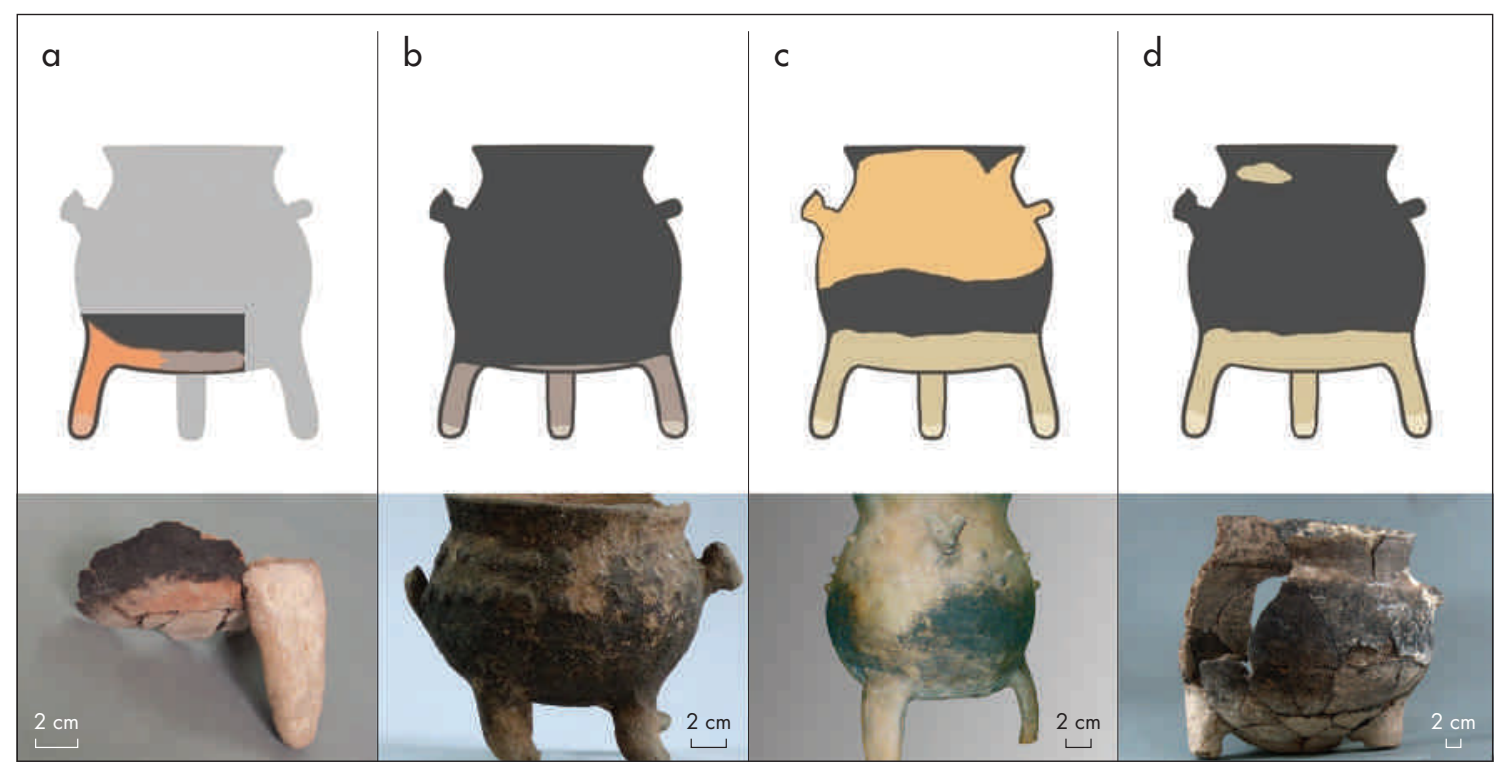

Figura 12. Tipos de depósitos de ollín en las ollas con patas. Figure 12. Soot deposits found on footed pots.

recinto 2 se encontraron fragmentos de un ejemplar de tamaño mediano, además de otros restos de cerámica ordinaria, una tinaja Belén asociada a una vasija modelada en forma de quirquincho (fig. 13), restos óseos de camélidos y de marlos de maíz, y parte de la enramada del techo carbonizada. El contexto fue interpretado como de consumo doméstico (Iucci 2013). En el recinto 54 se halló un fragmento de pata de una olla de tamaño chico, asociado a materiales Belén, Santa María y ordinarios con alto grado de fragmentación, una figurina de cerámica fracturada, artefactos líticos, deshechos de talla de obsidiana y restos esqueletales de animales, entre ellos camélidos; esto condujo a la interpretación del contexto como un patio o un sector para la realización de diversas actividades cotidianas, y puede considerarse la pata de la ollita como un producto de descarte.

Al pie del Cerro Colorado, sobre una terraza de inundación baja, en una zona con evidencias de prácticas relacionadas con la agricultura y dentro de un espacio semi-abierto, con escasos restos materiales, se halló un fragmento con pata y cuerpo de una olla muy chica.

En el sitio Loma de Ichanga, un poblado de solo 15 estructuras, se hallaron dos ejemplares bien representados de ollas con patas, una mediana y una chica, junto a fragmentos de una olla Belén y una vasija mediana de forma ovaloide con restos de pigmentos, que fueron reconstruidas completamente. Se dató el único fragmento de hueso conservado, identificado como de camélido. Los materiales y la disposición de los restos en esta estructura no ofrecen datos relacionados con el procesamiento de animales, pero sí es posible sugerir, a partir de la vajilla, un contexto de consumo de alimentos y de alguna actividad relacionada con la producción artesanal.

En el sitio El Molino las ollas con patas están representadas por un fragmento de cuerpo con aplicaciones de discos pequeños y una porción de cuello con una cabeza zoomorfa y discos en el recinto 68, y dos fragmentos de patas en el recinto 98. Dentro del valle, este sitio es el que cuenta con mayor cantidad de estructuras (alrededor de 110) y grado de aglomeración. Fue trabajado por A. R. González en la década de 1960 y no fue posible acceder a los registros y detalles de las excavaciones. La información que se pudo reconstruir indica que el recinto 98 corresponde a una estructura en forma de " $U$ ", protegida por otras estructuras y por la ladera de la loma. En su interior había cerámica Belén, Santa María y ordinaria, además de herramientas líticas. Debajo del piso se halló una vasija Santa María piriforme entera. González (1974) interpretó que se trataba de una estructura ceremonial. En relación al recinto 68 no se tiene mayor información, más allá de que presenta el mismo tipo de asociaciones cerámicas. Se obtuvo un fechado (Wynveldt \& Iucci 2013) de otro 


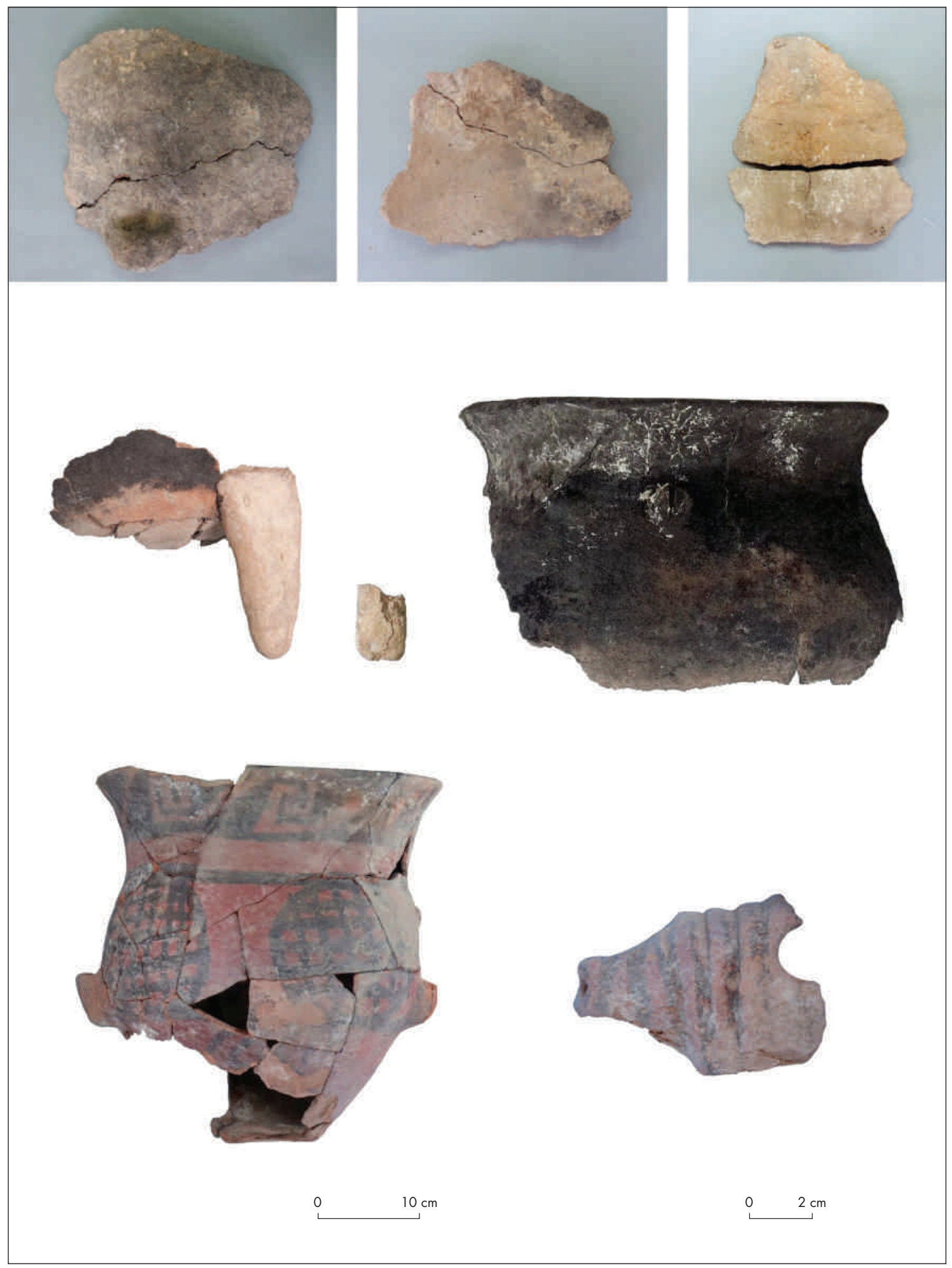

Figura 12. Piezas cerámicas asociadas en un contexto doméstico (recinto 2, Cerro Colorado). Figure 12. Ceramic pieces found in association with a domestic context (structure 2, Cerro Colorado). 
recinto, también excavado por A. R. González, realizado sobre restos esqueletales de un individuo sub-adulto que había sido enterrado en la estructura dentro de un contenedor cerámico tapado.

El resto de los materiales correspondientes a ollas con patas procedentes de los poblados fue hallado en recolecciones superficiales en El Molino y en Palo Blanco, un sitio tardío localizado en el centro del valle.

Por otra parte, entre las ollas con patas que pudieron localizarse en el área del valle se recuperaron cuatro de tamaño muy chico en entierros - todas de la Colección Benjamín Muñiz Barreto del Museo de La Plata-, de las cuales hasta el momento se ha podido obtener información contextual para dos, ambas relacionadas con la inhumación de niños. El primer caso (fig. 14) es una asociación de dos individuos en los alrededores del sitio El Molino. El contenedor corresponde al tipo definido como "tinaja ordinaria" (Iucci 2013), información que fue inferida a partir del dibujo realizado por el responsable de la excavación (Wolters 1924), ya que por su grado de fragmentación fue dejada en el campo. Estaba asociada a un puco que no se pudo localizar en la colección, y a una olla Belén. Esta última pieza responde morfológicamente a otras ollas de este tipo, no obstante, se diferencia en la calidad del modelado, del acabado de superficie y del trazo de las imágenes, que indican que probablemente no fue realizada por un alfarero experto. La otra vasija se encontró también dentro de una tinaja ordinaria, tapada por un puco ordinario, unos pocos kilómetros al este de El Molino. Además de la presencia de la olla Belén, que puede interpretarse como un indicador cronológico de momentos tardíos, el tipo de tinaja ordinaria que fue usada como contenedor ha podido ser reconocido en los pisos de las estructuras de los poblados con fechados, formando parte de prácticas ligadas al ámbito doméstico (Iucci 2013).

La cronología para el conjunto de asentamientos tardíos del valle indica que la mayor probabilidad de las dataciones se restringe a los siglos XV y XVI (tabla 5). Se consideran probabilidades para épocas algo más tempranas -no más allá de mediados del siglo XIV-y que algunos lugares hayan sido ocupados o re-ocupados durante el siglo XVII. A partir del total de fechados confiables disponibles se formularon diversos modelos para distinguir diferentes momentos de las ocupaciones (Wynveldt et al. 2017). En base a la información arqueológica, consideramos probable un modelo que distingue dos fases, una pre-Inka, en la que las ocupaciones datarían de los momentos inmediatamente previos a la presencia de enclaves imperiales en la zona, y una Inka, durante la que se hicieron efectivas las instalaciones cercanas de El Shinkal, Hualfín Inka y Quillay. Sin embargo, más allá del ajuste cronológico que pueda efectuarse a través de los fechados, no se observan diferencias significativas en la materialidad de la época que permitan establecer con claridad una secuencia independiente de la cronología absoluta entre momentos preinkas, inkas e, incluso, hispano-indígenas.

El tipo de ollas aquí analizadas pueden incluirse dentro de esta problemática. A través de la información arqueológica obtenida, queda claro que su presencia está ligada a las poblaciones locales tardías del valle, y se las encuentra en recintos con dataciones cuyas probabilidades pueden ubicarse tanto en la etapa pre-inka como en la época netamente inkaica, e incluso algo posterior.

\section{OLLAS, CAMÉLIDOS Y ÁMBITOS DE PARTICIPACIÓN: ALGUNAS LIINEAS INTERPRETATIVAS}

El intensivo proceso de remontaje a partir de fragmentos, y la comparación de las piezas obtenidas con vasijas completas de referencia, en su mayoría de colección, permitió la conformación de un grupo particular de ollas que no había sido trabajado sistemáticamente en la literatura arqueológica de la región valliserrana del Noroeste Argentino. Durante los inicios de un trabajo específico con la tradición de alfarería ordinaria local del Valle de Hualfín, se registró una serie de fragmentos imposible de asignar a sectores morfológicos reconocibles de vasijas; en este sentido, estos fragmentos constituían simples marcas, unidades mínimas a partir de las cuales no se podía construir una imagen con significado. Solo a través de la comparación con piezas enteras fue posible reconocer la ubicación de los distintos componentes, primero, e interpretar una imagen zoomorfa después. La localización de las marcas en el cuerpo de la vasija y algunas particularidades de los modelados adheridos al cuerpo, como por ejemplo la incisión o escotadura del sector de apoyo de las patas, se encuentran entre las claves que sirvieron para encontrar en estas vasijas un camélido de pie, y así marcar su vigencia como representación en las poblaciones tardías del valle.

Estas imágenes están construidas en tres dimensiones, de modo que la representación del cuerpo del 
Tabla 5. Fechas de ${ }^{14} \mathrm{C}$ calibradas para los sitios tardíos del Valle de Hualfín. Las fechas para contextos de ollas con patas están en gris claro en el nivel de asociación de sitio y oscuro en el nivel de estructura (calibrado con OxCal v 4.2.4, Bronk Ramsey y Lee 2013). Modificado de Wynveldt y colaboradores (2017). Table 5. ${ }^{14} \mathrm{C}$ calibrated dates for late Hualfin Valley sites. Dates for footed pot contexts are shown in light grey for site level association and dark grey for structure (calibrated with OxCal v 4.2.4, Bronk Ramsey and Lee 2013). Modified from Wynveldt et al. (2017).

\begin{tabular}{|c|c|c|c|c|c|}
\hline \multirow[t]{2}{*}{ SITIO } & \multirow[t]{2}{*}{ CÓDIGO } & \multirow[t]{2}{*}{ MUESTRA } & \multirow{2}{*}{$\begin{array}{c}\text { EDAD C-14 } \\
\text { Convencional AP }\end{array}$} & \multicolumn{2}{|c|}{ CALIBRACIÓN AD (Curva SHcal13) } \\
\hline & & & & $1 \sigma(68,2 \%$ prob. $)$ & $2 \sigma(95,4 \%$ prob. $)$ \\
\hline \multirow[t]{3}{*}{ Loma de los Antiguos, R10 } & \multirow[t]{3}{*}{ LP-872 } & \multirow[t]{3}{*}{ Carbón } & \multirow[t]{3}{*}{$220 \pm 70$} & $1648-1708(20,4 \%)$ & \multirow{3}{*}{$\begin{array}{c}1513-1546(2,9 \%) \\
1623-1949(92,5 \%)\end{array}$} \\
\hline & & & & $1721-1811(34,1 \%)$ & \\
\hline & & & & $1837-1949(13,6 \%)$ & \\
\hline \multirow[t]{3}{*}{ Cerro Colorado, R35 } & \multirow[t]{3}{*}{ LP-2760 } & \multirow{3}{*}{$\begin{array}{l}\text { Marlo de maíz } \\
\text { carbonizado }\end{array}$} & \multirow[t]{3}{*}{$290 \pm 60$} & $1509-1580(26,6 \%)$ & $1461-1700(70,2 \%)$ \\
\hline & & & & $1621-1672(25,9 \%)$ & $1722-1810(23,6 \%)$ \\
\hline & & & & $1743-1796(15 \%)$ & \\
\hline \multirow{3}{*}{$\begin{array}{l}\text { Campo de Carrizal, } \\
\text { E2 NH1 R1 }\end{array}$} & \multirow[t]{3}{*}{ LP-1250 } & \multirow[t]{3}{*}{ Carbón } & \multirow[t]{3}{*}{$310 \pm 60$} & $1502-1593(40,9 \%)$ & $1459-1681(81,4 \%)$ \\
\hline & & & & $1613-1667(25,9 \%)$ & $1730-1802(14 \%)$ \\
\hline & & & & $1789-1791(0,7 \%)$ & \\
\hline \multirow[t]{2}{*}{ Loma de los Antiguos, R31 } & \multirow[t]{2}{*}{ LP-1644 } & \multirow{2}{*}{ Hueso humano } & \multirow[t]{2}{*}{$320 \pm 50$} & $1506-1587(45,7 \%)$ & $1463-1672(90,8 \%)$ \\
\hline & & & & $1618-1654(22,5 \%)$ & $1744-1759(2 \%)$ \\
\hline Lajas Rojas, R2 & LP-1793 & Carbón & $320 \pm 60$ & $1502-1594(42,6 \%)$ & $1459-1675(85,6 \%)$ \\
\hline & & & & $1613-1661(25,6 \%)$ & $1737-1798(9,8 \%)$ \\
\hline Loma de los Antiguos, R9 & LP-937 & Carbón & $330 \pm 50$ & $1505-1588(48,8 \%)$ & $1460-1670(94,1 \%)$ \\
\hline & & & & $1617-1649(19,4 \%)$ & $1749-1752(0,2 \%)$ \\
\hline Loma de los Antiguos, R3 & LP-1039 & Carbón & $350 \pm 50$ & $1502-1593(54,2 \%)$ & $1460-1654(95,4 \%)$ \\
\hline & & & & $1613-1638(14 \%)$ & \\
\hline Loma de Ichanga, R9 & LP-2667 & Hueso de Camelidae & $360 \pm 50$ & $1500-1597(56,3 \%)$ & $1460-1648(95,4 \%)$ \\
\hline & & & & $1611-1632(11,9 \%)$ & \\
\hline Loma de Ichanga, R6 & LP-1832 & Marlo de maíz carbonizado & $420 \pm 50$ & $1449-1510(42,6 \%)$ & $1443-1629(95,4 \%)$ \\
\hline & & & & $1578-1621(25,6 \%)$ & \\
\hline Cerrito Colorado, R8 & LP- 2309 & Carbón & $420 \pm 70$ & $1448-1512(35,4 \%)$ & $1427-1645(95,4 \%)$ \\
\hline & & & & $1548-1563(5,5 \%)$ & \\
\hline & & & & $1570-1623(27,3 \%)$ & \\
\hline Cerrito Colorado, R3 & LP-1810 & Carbón & $420 \pm 70$ & $1448-1512(35,4 \%)$ & $1427-1645(95,4 \%)$ \\
\hline & & & & $1548-1563(5,5 \%)$ & \\
\hline & & & & $1570-1623(27,3 \%)$ & \\
\hline Campo de Carrizal, & LP-2330 & Carbón & $430 \pm 60$ & $1443-1510(43,3 \%)$ & $1430-1633(95,4 \%)$ \\
\hline E3 NH2 R1 & & & & $1554-1556(0,7 \%)$ & \\
\hline & & & & $1576-1622(24,2 \%)$ & \\
\hline Cerro Colorado, R2 & AA105209 & Carbón & $446 \pm 25$ & $1447-1486(68,2 \%)$ & $1440-1504(84,9 \%)$ \\
\hline & & & & & $1591-1615(10,5 \%)$ \\
\hline Lajas Rojas, R4 & LP-2651 & Marlo de maíz carbonizado & $460 \pm 50$ & $1432-1500(60 \%)$ & $1412-1515(70,6 \%)$ \\
\hline & & & & $1597-1611(8,2 \%)$ & $1540-1625(24,8 \%)$ \\
\hline Cerro Colorado, R35 & AA100176 & Marlo de maíz carbonizado & $478 \pm 38$ & $1429-1465(60 \%)$ & 1411-1502 (89,7\%) \\
\hline & & & & $1467-1477(8,2 \%)$ & $1593-1614(5,7 \%)$ \\
\hline Cerro Colorado, R2 & AA94600 & Marlo de maíz carbonizado & $493 \pm 34$ & $1428-1456(68,2 \%)$ & $1408-1488(95,4 \%)$ \\
\hline La Estancia, R13 & AA105210 & Marlo de maíz carbonizado & $512 \pm 35$ & $1422-1451(68,2 \%)$ & $1400-1464(95,4 \%)$ \\
\hline Loma de Palo Blanco, R34 & AA105211 & Larrea sp. carboizada & $523 \pm 26$ & $1421-1445(68,2 \%)$ & $1410-1452(95,4 \%)$ \\
\hline Loma de la Escuela Vieja, R6 & AA88362 & Marlo de maíz carbonizado & $521 \pm 36$ & $1419-1447(68,2 \%)$ & $1401-1458(95,4 \%)$ \\
\hline Cerro Colorado, R36 & AA85880 & Hueso humano & $539 \pm 43$ & $1409-1443(68,2 \%)$ & $1327-1340(1,9 \%)$ \\
\hline & & & & & $1390-1460(93,5 \%)$ \\
\hline El Molino, R110 & AA88363 & Hueso humano & $585 \pm 44$ & $1328-1336(6,8 \%)$ & $1315-1357(23,5 \%)$ \\
\hline & & & & $1391-1433(61,4 \%)$ & $1381-1448(71,9 \%)$ \\
\hline Pueblo Viejo de El Eje, R53 & AA94601 & Hueso de Lama sp. & $602 \pm 42$ & $1323-1345(22,8 \%)$ & $1308-1361(36,3 \%)$ \\
\hline & & & & $1388-1421(45,4 \%)$ & $1378-1441(59,1 \%)$ \\
\hline
\end{tabular}




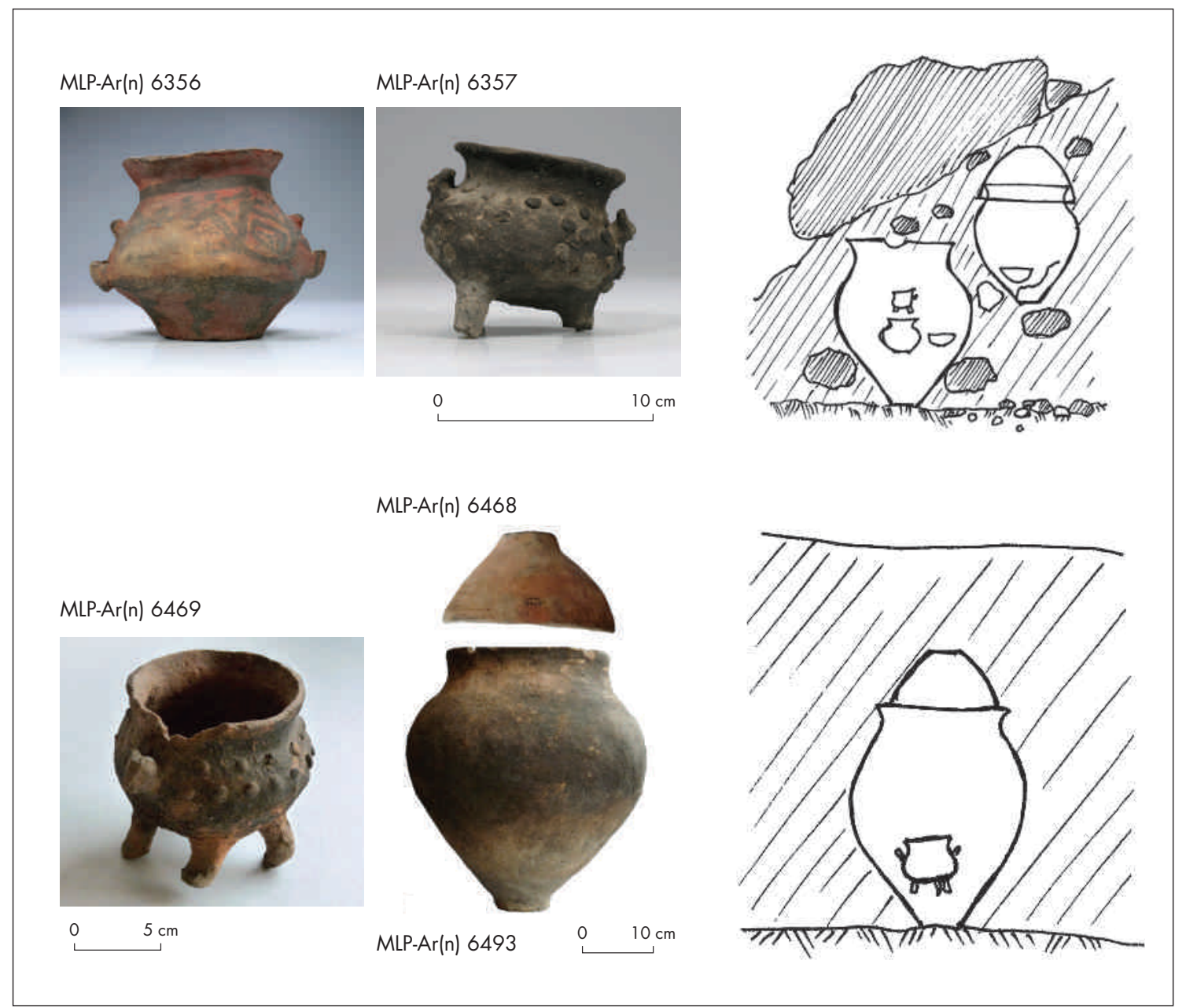

Figura 14. Asociaciones cerámicas en los entierros en donde se hallaron ollas con patas. Los sepulcros se redibujaron de Wolters (1924). Figure 14. Ceramic associations in graves containing footed pots. Graves are re-drawn from Wolters (1924).

animal participaba en el ámbito de la práctica no solo como imagen, sino también como vasija. Ya desde el momento de la producción alfarera, para la confección se usaban recetas afines al resto de la alfarería ordinaria, por ejemplo, a partir del añadido de tiesto molido y de la elaboración de acabados superficiales similares. Así, se producía un contenedor, cuyas características de modelado y de manufactura en general son adecuadas para funciones mecánicas como contener, calentar y trasladar sustancias en diferentes cantidades. Las huellas de uso evidencian que participaron efectivamente -además de su uso más notorio como acompañamiento funerarioen diversas actividades. El importante vínculo con el fuego y, por consiguiente, con la cocción de alimentos, uno de los aspectos más sobresalientes de la alfarería ordinaria, es una cualidad que no escapa a las ollas con patas. Más allá de que aún desconocemos el tipo de contenido específico que pudo haberse introducido, las caracterizaciones de los contextos permiten pensar en comidas y bebidas asociadas con el maíz y los camélidos, entre otros alimentos tradicionales reportados para el área. Las piezas muy chicas pueden vincularse al calentamiento y consumo de bebidas en circunstancias rituales -como por ejemplo un entierro, mientras eran depositadas en el contenedor junto al difunto, a modo de ofrenda. Los contextos de hallazgo de las piezas más grandes indican que actuaban frecuentemente en las dinámicas de preparación de alimentos -en diversas circunstancias como la producción artesanal y en las tareas relacionadas con el cultivo-. Sin embargo, no se 
descarta su eventual participación como urna funeraria o acompañamiento, teniendo en cuenta que muy probablemente las piezas enteras para las que no contamos con el registro de su procedencia hayan sido extraídas de sepulcros. Observada desde este punto de vista, las ollas con patas, al igual que el resto de la alfarería ordinaria y la cerámica Belén asociada, probablemente circularon por circuitos amplios de acción y no por canales restringidos, como podrían ser los vinculados a elites políticas o religiosas.

De este modo, la imagen camélido se materializaba en un tipo de objeto contenedor con participación en diferentes circunstancias y por lo tanto interviniendo en diferentes semiosis posibles. Su inserción específica en las diversas situaciones de interacción social permite situarla a modo de mediador en redes de relaciones de distinta escala: la referencia de la imagen a un animal de profunda conexión con las poblaciones humanas, por supuesto en toda el área andina, pero también específicamente en el valle; la participación del objeto vasija en tanto contenedor, y la acción simultánea de la imagen del objeto vasija en diversos ámbitos de la práctica, con el potencial de significados que su imagen -en tanto camélido y en tanto vasija- pudo evocar y reproducir en las coyunturas específicas de las sociedades del valle entre los siglos XV y XVI.

Por otro lado, es destacable que, para elaborar la imagen, se alcanza una representación figurativa a partir de la combinación de unos pocos elementos, sin la necesidad de disponer de todas las unidades de la imagen para recrear el referente. De esta manera, una pregunta que queda planteada es si la presencia de las mismas unidades mínimas que pudimos aislar en las ollas con patas en vasijas de otras morfologías podría aludir al mismo referente. Pueda o no responderse esta pregunta, lo cierto es que en la cerámica ordinaria tardía de la zona abundan las imágenes icónicas. La cerámica fina, principalmente la Belén, es uno de los tipos mayoritarios en el registro material tardío del Valle de Hualfín, y participa del espacio de la práctica de maneras muy diversas. A través de sus imágenes se han podido identificar esquemas cognitivos de sus productores, asociaciones entre los referentes existenciales y sus funciones prácticas, preferencias estéticas y expresiones de la interacción entre grupos sociales de diverso origen. El ejercicio de profundizar la búsqueda y reconstrucción de vasijas ordinarias pone en evidencia la necesidad de incorporar la producción y el significado de sus imágenes para comprender el alcance de los temas representados en la alfarería tardía de los habitantes de la región.

\section{REFERENCIAS}

BALesta, B. 2000. La significación en la funebria de La Ciénaga. Tesis doctoral, Facultad de Ciencias Naturales y Museo, Universidad Nacional de La Plata.

BALESTA, B. 2015. Interpretaciones semióticas sobre imágenes de camélidos en el Noroeste Argentino. Boletín del Museo Chileno de Arte Precolombino 20 (1): 9-28.

Balesta, B. \& Williams, V. 2007. El análisis cerámico desde 1936 hasta nuestros días. Relaciones de la Sociedad Argentina de Antropología XxxII: 169-190.

Balesta, B., Zagorodny, N. \& Wynveldt, F. 2011. La configuración del paisaje Belén (Valle de Hualfín, Catamarca). Relaciones de la Sociedad Argentina de Antropología Xxxvi: 149-175.

BASILE, M. 2009. Recorriendo trazos. Un aporte a la definición de estilo decorativo Belén. Arqueología 15: 13-40.

Bregante, O. 1926. Ensayo de clasificación de la cerámica del Noroeste Argentino. Buenos Aires: Estrada.

Bronk Ramsey C \& Lee, S. 2013. Recent and planned developments of the program OxCal. Radiocarbon 55 (2-3): 720-730.

Costin, C. L. 2001. Craft production systems. En Archaeology at the millennium: a sourcebook, G. Feinman \& T. Price, Eds., pp. 273-327. Nueva York: Kluwar Academic/Plenum Press.

Debenedetti, S. 1921. La influencia hispánica en los yacimientos arqueológicos de Caspinchango (Provincia de Catamarca). Publicaciones de la Facultad de Filosofía y Letras, Sección Antropología 20. Facultad de Filosofía y Letras de la Universidad de Buenos Aires, Buenos Aires.

De La Fuente G. 2007. Producción y tecnología cerámica en Watungasta: estandarización, especialización y procedencia (Valle de Abaucán, Dpto. Tinogasta, Pcia. de Catamarca, Argentina). Tesis doctoral. Facultad de Ciencias Naturales y Museo, Universidad Nacional de La Plata.

De La Fuente G. 2011. Urns, bowls and ollas. Pottery making practices and technical identity in the Southern Andes during the Late Period (ca. 900-1450) (Catamarca, Northwestern Region, Argentina). Latin American Antiquity 22 (2): 224-252.

GASTALDI, M. 2010. Cultura material, construcción de identidades y transformaciones sociales en el Valle de Ambato durante el primer milenio DC. Tesis Doctoral. Facultad de Ciencias Naturales y Museo, Universidad Nacional de La Plata.

GonzÁLEZ, A. R. 1955. Contextos culturales y cronología relativa en el área central del NO Argentino (nota preliminar). Anales de Arqueología y Etnología 11: 7-32.

GonzÁlez, A. R. 1972. The felinic complex in Northwest Argentina. En The cult of the feline, E. Benson, Ed., pp. 
117-138. Washington: Dumbarton Oaks, Trustees for Harvard University.

GonzÁlez, A. R. 1974. Arte, estructura y antropología. Buenos Aires: Nueva Visión.

González, A. R. \& Cowgill, G. 1975. Cronología arqueológica del Valle de Hualfín, Catamarca, Argentina. En Actas del Primer Congreso de Arqueología Argentina, pp. 383-404. Rosario.

Grant, J. \& Escola, P. 2015. La persistencia de un modo de producción doméstico durante el Período Tardío: el caso de Corral Alto (Antofagasta de la Sierra, Argentina). Estudios Atacameños 51: 99-121.

IUCCI, M. E. 2009. Caracterización de la forma, tamaño y función de las vasijas ordinarias de Puerta de Corral Quemado (Dpto. de Belén, Prov. de Catamarca). Comechingonia 12: 31-54.

IUCCI, M. E. 2013, Producción, circulación y uso de cerámica tardía en el Valle de Hualfín (Catamarca, Argentina). Tesis doctoral, Facultad de Ciencias Naturales y Museo, Universidad Nacional de La Plata. <http://sedici.unlp. edu.ar/handle/10915/35235> [consultado 05-06-2019]

Iucci, M. E., Volzone, C., Morosi M. \& Zagorodny, N. 2010. Aporte del análisis textural por porosimetría de mercurio a la caracterización de la cerámica ordinaria del sitio El Molino (Depto. de Belén, Catamarca). En La arqueometría en Argentina y Latinoamérica, S. Bertolino, R. Cattáneo, \& A. Izeta, Eds., pp. 57-72. Córdoba: Editorial de la Facultad de Filosofía y Humanidades.

LAfone Quevedo, S. 1892. Catálogo descriptivo e ilustrado de las Huacas de Chañar Yaco. Revista del Museo de La Plata 3: 33-63.

Latour, B. 2008. Reensamblar lo social. Buenos Aires: Manantial.

Lorenzo, G. 2017. Primera aproximación al conjunto arqueofaunístico del sitio Cerro Colorado de La Ciénaga de Abajo (Catamarca). Cuadernos del Instituto Nacional de Antropología y Pensamiento Latinoamericano 4 (4): 39-48.

Lorenzo, G. S \& DEL PAPA, L. M. 2018. El registro zooarqueológico en Campo de Carrizal de Asampay: indagando sobre los contextos de uso de la fauna por parte de los pobladores tardíos del Valle de Hualfín (Departamento de Belén, Catamarca). En Las dimensiones del paisaje tardío en el Valle de Hualfín (Belén, Catamarca), F. Wynveldt \& B. Balesta, Eds., pp. 233-266. Buenos Aires: Sociedad Argentina de Antropología.

Madero, C. M. 1993-94. Ganadería incaica en el Noroeste Argentino: análisis de la arqueofauna de dos poblados prehispánicos. Relaciones de la Sociedad Argentina de Antropología XIX: 145-169.

Magariños de Morentín, J. 2001. La(s) semiótica(s) de la imagen visual. Cuadernos de la Facultad de Humanidades y Ciencias Sociales 17: 295-320.

Magariños de Morentín, J. 2008. La semiótica de los bordes. Apuntes de metodología semiótica. Córdoba: Comunicarte.
Marchegiani, M. 2011. Las formaciones sociales de Yocavil durante la dominación inca y la conquista española. Contacto, conflicto, persistencia y transformaciones (siglos XV-XVII DC). Tesis doctoral inédita, Facultad de Filosofía y Letras, Universidad de Buenos Aires.

Marchegiani M. \& Greco, C. 2007. Tecnología, estilo y cronología de la cerámica ordinaria de Rincón Chico, Valle de Yocavil, Catamarca. Resúmenes ampliados del XVI Congreso Nacional de Arqueología Argentina, Tomo II, pp. xxxx. San Salvador de Jujuy: Facultad de Humanidades y Ciencias Sociales, Universidad Nacional de Jujuy.

Martel, A. \& Giraudo, S. 2014. Semiótica de la imagen en arqueología: el caso de los "escutiformes". Revista Chilena de Antropología Visual 24: 21-45.

MenAcho, K. 2007. Etnoarqueología y estudios sobre funcionalidad cerámica: aportes a partir de un caso de estudio. Intersecciones en Antropología 8: 149-161.

Mercolli, J. P. 2011. El truco está en la diversidad: estrategias de manejo pastoril en la Quebrada de Humahuaca, Provincia de Jujuy, Argentina entre el 900 y el 1200 AD. Revista Arqueología 17: 81-95.

Moreno, E. \& Revuelta, C. 2010. La cacería de vicuñas en el oasis de Tebenquiche Chico (Siglos III-VIII y XVI-XVII DC). En Zooarqueología a principios del siglo XXI. Aportes teóricos, metodológicos y casos de estudio, M. A. Gutiérrez, M. De Nigris, P. M. Fernández, M. Giardina, A. Gil, A. Izeta, G. Neme. \& H. Yacobaccio, Eds., pp. 285-296. Buenos Aires: Ediciones del Espinillo.

NASTRI, J. 2008. La figura de las largas cejas de la iconografía santamariana. Chamanismo, sacrificio y cosmovisión calchaquí. Boletín del Museo Chileno de Arte Precolombino 13 (1): 9-34.

PÁEz, M. C. 2010. Tecnología alfarera del último milenio de ocupación aborigen del valle de Tafí (prov. de Tucumán). Tesis doctoral. Facultad de Ciencias Naturales y Museo, Universidad Nacional de La Plata.

Palamarczuk V. 2009. Un estilo y su época. El caso de la cerámica Famabalasto Negro Grabado del Noroeste Argentino. Tesis doctoral. Facultad de Filosofía y Letras, Universidad de Buenos Aires.

Pérez, M. \& Velázquez Cabrera, R. 2015. Análisis de llamas resonadoras de arcilla (Jujuy, Puna septentrional argentina). Revista Arqueología 21 (1): 13-29.

PIÑEIRo M. 1996. Manejo de recursos y organización de la producción cerámica en Rincón Chico, Catamarca. Relaciones de la Sociedad Argentina de Antropología xxi: 161-185.

Podestá, C. \& Perrota, E. B. 1973. Relaciones entre culturas del Noroeste Argentino. San José y Santa María. Antiquitas 17: 6-15. Buenos Aires.

Puente, V. 2012. "Atravesando fronteras". Prácticas compartidas e identidades sociales negociadas durante el Tardío Prehispánico. Una discusión desde la alfarería ordinaria del Valle del Bolsón (Belén, Catamarca). Relaciones de la Sociedad Argentina de Antropología xxxviI: 65-87. 
QUIRoga L. \& Puente, V. 2007. Imagen y percepción: iconografía de las urnas Belén. Colección Schreiter. En Procesos sociales prehispánicos en el sur andino. La vivienda, la comunidad y el territorio, A. Nielsen, M. C. Rivolta, V. Seldes, M. M. Vásquez, \& P. Mercolli, Eds., pp. 323-346. Colección Historia Social Precolombina 1. Córdoba: Brujas.

Rice, P. 1987. Pottery analysis. A sourcebook. Chicago: University of Chicago Press.

Roux, V. 2003. Ceramic standardization and intensity of production: quantifying degrees of specialization. American Antiquity 68 (4): 768-782.

Serrano, A. 1958. Manual de la cerámica indígena. Córdoba: Ediciones Assandri.

Sillar B. \& Tite, M. 2000. The challenge of 'technological choices' for material science approaches in archaeology. Archaeometry 42 (1): 2-20.

SкIво, J. 1992. Pottery function. A use-alteration perspective. Nueva York-Londres: Plenum Press.

Tarragó, M. N. 1984. El contacto hispano-indígena: la Provincia de Chicoana. Runa 14: 143-185.

Willats, J. 1994. El contrato del dibujante: cómo crea imágenes el artista. En Imagen y conocimiento, H. Barlow, C. Blakemore \& M. Weston-Smith, Eds., pp. 169-190. Barcelona: Crítica.

Wolters, F. 1924 Ms. Cuaderno de registro. Museo de La Plata.
Wynveldt, F. 2009. La Loma de los Antiguos de Azampay. Un sitio defensivo del valle de Hualfín (Catamarca, Argentina). Buenos Aires: Sociedad Argentina de Antropología.

Wynveldt, F., Balesta, B., Iucci, M. E., Valencia, C. \& Lorenzo, G. 2017. Late chronology in Hualfin valley (Catamarca, Argentina): a revisión from ${ }^{14} \mathrm{C}$ dating. Radiocarbon 59 (1): 91-107.

Wynveldt, F. \& Iucci, M. E. 2013. La cronología Belén en el norte del valle de Hualfín: viejos problemas, nuevas perspectivas. Revista Arqueología 19 (1): 187-195.

Wynveldt, F. \& Flores, M. 2014. La obsidiana en el paisaje tardío del valle de Hualfín (Depto. de Belén, Prov. de Catamarca). Revista Arqueología 20: 193-216.

ZABurLín, M. A. 2016. Vasijas zoomorfas prehispánicas de la puna de Jujuy (Argentina). Una propuesta de análisis semiótico. Boletín del Museo Chileno de Arte Precolombino 21 (2): 137-152.

Zagorodny, N. 1996. Un estudio tecnológico sobre la alfarería doméstica en el Temprano. Actas y memorias del XI Congreso Nacional de Arqueología Argentina. 11 a Parte. Revista del Museo de Historia Natural de San Rafael. Tomo XXIII 1/4. Mendoza.

Zagorodny, N., Morosi, M., Iucci, M. E. \& Wynveldt, F. 2010. Estudios composicionales de las pastas de cerámica tardía del Valle de Hualfín (Belén. Catamarca). Revista Arqueología 16: 125-150. 